University of Nebraska - Lincoln

DigitalCommons@University of Nebraska - Lincoln

USDA Forest Service / UNL Faculty Publications U.S. Department of Agriculture: Forest Service -National Agroforestry Center

2005

\title{
Testing the potential of multi-spectral remote sensing for retrospectively estimating fire severity in African Savannahs
}

\author{
Alistair M.S. Smith \\ University of Idaho, alistair@uidaho.edu \\ Martin J. Wooster \\ King's College London, martin.wooster@kcl.ac.uk \\ Nick A. Drake \\ King's College London, nick.drake@kcl.ac.uk \\ Frederick M. Dipotso \\ Department of Wildlife and National Parks \\ Michael J. Falkowski \\ Michigan Technological University, mjfalkow@mtu.edu \\ See next page for additional authors
}

Follow this and additional works at: https://digitalcommons.unl.edu/usdafsfacpub

Smith, Alistair M.S.; Wooster, Martin J.; Drake, Nick A.; Dipotso, Frederick M.; Falkowski, Michael J.; and Hudak, Andrew T., "Testing the potential of multi-spectral remote sensing for retrospectively estimating fire severity in African Savannahs" (2005). USDA Forest Service / UNL Faculty Publications. 208. https://digitalcommons.unl.edu/usdafsfacpub/208

This Article is brought to you for free and open access by the U.S. Department of Agriculture: Forest Service -National Agroforestry Center at DigitalCommons@University of Nebraska - Lincoln. It has been accepted for inclusion in USDA Forest Service / UNL Faculty Publications by an authorized administrator of DigitalCommons@University of Nebraska - Lincoln. 


\section{Authors}

Alistair M.S. Smith, Martin J. Wooster, Nick A. Drake, Frederick M. Dipotso, Michael J. Falkowski, and Andrew T. Hudak 


\title{
Testing the potential of multi-spectral remote sensing for retrospectively estimating fire severity in African Savannahs
}

\author{
Alistair M.S. Smith ${ }^{\mathrm{a}, *}$, Martin J. Wooster ${ }^{\mathrm{b}}$, Nick A. Drake ${ }^{\mathrm{b}}$, Frederick M. Dipotso ${ }^{\mathrm{c}}$, \\ Michael J. Falkowski ${ }^{\text {a }}$, Andrew T. Hudak ${ }^{\mathrm{d}}$ \\ a Department of Forest Resources, University of Idaho, Moscow, Idaho, 83844, USA \\ ${ }^{\mathrm{b}}$ Department of Geography, King's College London, London, WC2R 2LS, UK \\ ${ }^{\mathrm{c}}$ Research Division, Department of Wildlife and National Parks, Box 17 Kasane, Botswana \\ ${ }^{\mathrm{d}}$ Rocky Mountain Research Station, USDA Forest Service, Moscow, Idaho, 83843, USA
}

Received 2 June 2004; received in revised form 26 April 2005; accepted 29 April 2005

\begin{abstract}
The remote sensing of fire severity is a noted goal in studies of forest and grassland wildfires. Experiments were conducted to discover and evaluate potential relationships between the characteristics of African savannah fires and post-fire surface spectral reflectance in the visible to shortwave infrared spectral region. Nine instrumented experimental fires were conducted in semi-arid woodland savannah of Chobe National Park (Botswana), where fire temperature $\left(T_{\max }\right)$ and duration $(\mathrm{dt})$ were recorded using thermocouples positioned at different heights and locations. These variables, along with measures of fireline intensity (FLI), integrated temperature with time ( $\left.T_{\text {sum }}\right)$ and biomass (and carbon/nitrogen) volatilised were compared to post-fire surface spectral reflectance. Statistically significant relationships were observed between (i) the fireline intensity and total nitrogen volatilised $\left(r^{2}=0.54, n=36, p<0.001\right)$, (ii) integrated temperature $\left(T_{\text {sum- }} \mu\right)$ and total biomass combusted $\left(r^{2}=0.72, n=32, p<0.001\right)$, and (iii) fire duration as measured at the top-of-grass sward thermocouple $\left(\mathrm{dt}_{\mathrm{T}}\right)$ and total biomass combusted $\left(r^{2}=0.74, n=34, p<0.001\right)$ and total nitrogen volatilised $\left(r^{2}=0.73, n=34, p<0.001\right)$. The post-fire surface spectral reflectance was found to be related to dt and $T_{\text {sum }}$ via a quadratic relationship that varied with wavelength. The use of visible and shortwave infrared band ratios produced statistically significant linear relationships with fire duration as measured by the top thermocouple $\left(\mathrm{dt}_{\mathrm{T}}\right)$ $\left(r^{2}=0.76, n=34, p<0.001\right)$ and the mean of $T_{\text {sum }}\left(r^{2}=0.82, n=34, p<0.001\right)$. The results identify fire duration as a versatile measure that relates directly to the fire severity, and also illustrate the potential of spectrally-based fire severity measures. However, the results also point to difficulties when applying such spectrally-based techniques to Earth Observation satellite imagery, due to the small-scale variability noted on the ground. Results also indicate the potential for surface spectral reflectance to increase following higher severity fires, due to the laying down of high albedo white mineral ash. Most current techniques for mapping burned area rely on the general assumption that surface albedo decreases following a fire, and so if the image spatial resolution was high enough such methods may fail. Determination of the effect of spatial resolution on a sensor's ability to detect white ash was investigated using a validated optical mixture modelling approach. The most appropriate mixing model to use (linear or non-linear) was assessed using laboratory experiments. A linear mixing model was shown most appropriate, with results suggesting that sensors having spatial resolutions significantly higher than those of Landsat ETM + will be required if patches of white ash are to be used to provide EO-derived information on the spatial variation of fire severity.
\end{abstract}

(C) 2005 Elsevier Inc. All rights reserved.

Keywords: Fire severity; Savannah; Surface reflectance; Char; Nitrogen; Carbon; Burn severity index; Linear and non-linear spectral unmixing; Elemental emission factor

\footnotetext{
* Corresponding author. Tel.: +1 208885 1009; fax: +1 2088856226 .

E-mail address: alistair@uidaho.edu (A.M.S. Smith).
}

\section{Introduction}

Global biomass burning is a major component of the Earth's biogeochemical cycle and is thought to be account for over $40 \%$ of anthropogenic carbon dioxide and carbon 
monoxide emissions (Houghton et al., 1995; Levine, 1996). It is believed that eighty percent of all biomass burning occurs in the tropics, and some estimates suggest that nearly twenty percent of all biomass burning emissions originate from African savannah fires (Andreae, 1997; Coffer et al., 1996; Hao \& Liu, 1994). This combustion process has a direct and significant influence on Earth's vegetation, soils, atmospheric chemistry and radiative budget and so requires careful investigation (Andreae \& Merlet, 2001; Crutzen \& Andreae, 1990; Scholes \& Andreae, 2000; Scholes et al., 1996).

The large-scale nature of fires, including those in southern Africa, has encouraged the development of several spectral techniques employing satellite imagery to remotely determine fuel and fire characteristics. Thermal measurements have been used to locate active fires (e.g. Roy et al., 1999) and estimate the rate of radiative energy release during burning (Kaufman et al., 1998; Wooster, 2002; Wooster et al., 2003; Wooster \& Zhang, 2004), while optical measurements of the pre- and post-burn surface spectral reflectance has been used to map the spatial extent of burned areas (e.g. Eva \& Lambin, 1998; Hudak \& Brockett, 2004; Smith et al., 2002; Trigg \& Flasse, 2001). Despite these advances, relatively little attention has been paid to the actual spectral properties of the solid combustion products (i.e. the ash resulting from the fire), and the potential relationships that may exist between these products and the fire characteristics (Pereira et al., 1997; Pereira et al., 1999). In savannah and other fires, two ash endmembers occur, white 'mineral' ash where fuel has undergone complete combustion, and darker 'black' ash or char where an unburned fuel component remains. A preliminary field study conducted by Stronach (1989) indicated that ash albedo increases with increasing fireline intensity; while McNaughton et al. (1998) suggested that such a relationship might be used with remote sensing systems to provide a method of retrospectively estimating fire characteristics over large areas. This increase in ash reflectance after intense fires may also have implications for the ability of EO burned area mapping techniques to discriminate the highest intensity fires, since most such algorithms rely on detecting areas of decreased surface albedo related to burning.

In a recent study of southern African savannah fires using the Landsat Thematic Mapper (TM), Landmann (2003) observed that the abundance of white ash derived from linear spectral unmixing was related to variation in the pre-fire fuel load, and so the former may act as an indicator of the proportion of available fuel combusted. Such findings are important because current knowledge of the spatial and temporal variations in fire characteristics (intensity, severity, duration, etc) is poorly constrained, and this is one of the key uncertainties in quantifying fire effects, including those on the terrestrial carbon and nitrogen cycles (French et al., 2004; GTOS, 2000; Kasischke \& Bruhwiler, 2003). The remote sensing of fire characteristics is therefore a noted goal in wildfire research, and the above-mentioned studies suggest that satellite Earth observation may ultimately hold the potential to provide spatial-temporal information on certain of the key parameters. Experiments are therefore required in order to investigate potential relationships between fire intensity, fuel volatised, and ash spectral reflectance. Using instrumented, experimental fire plots and ground-based remote sensing techniques, this study examines potential relationships between post-fire visible to shortwave infrared surface spectral reflectance and certain of these parameters. The potential of high spatial-resolution EO sensors to remotely determine measures relating to fire severity variations is then evaluated.

\section{Background: fire severity and intensity}

In order to appropriately describe fire characteristics and the effect of fire on the environment, clarification of the terms fire intensity and fire severity are required since they are often confused (Díaz-Delgado et al., 2003; Waldrop \& Brose, 1999). Fire intensity is a description of fire behavior (Byram, 1959a; Morgan et al., 2001), as quantified by the temperature of the flaming front and the heat released by it (Neary et al., 1999). Fire severity is a measure of fire effects (Morgan et al., 2001), which can be described by the degree of mortality in aboveground vegetation (Miller \& Yool, 2002) or by the degree to which the fire alters soil properties and below ground processes (Neary el al., 1999). The term fire severity has also been used to describe fire duration, which is sometimes combined with information on fire temperature (Jacoby et al., 1992; Perez \& Moreno, 1998). Measures of fire duration and fire temperature integrated over time potentially provide information on the fires potential damage to vegetation, in its ability to stimulate or hinder soil microbial process, or promote germination (Perez \& Moreno, 1998; Stronach, 1989). Although the intensity of a fire often dictates its severity, the two phenomena are not always well correlated (Hartford \& Frandsen, 1992; Neary et al., 1999).

The majority of fires occurring in tropical grasslands, savannahs and woodlands are primarily supported by the herbaceous fuel load (in which grass species dominate), whereas the living trees typically do not burn (Stronach \& McNaughton, 1989; Trollope, 1996; West, 1971). Longterm vegetation mortality, following even the most intense fires, is generally not observed, but rather the grasses regrow and re-absorb carbon, nitrogen and other elements during subsequent growing seasons (Andreae, 1991; Hao et al., 1991; Houghton, 1991; Trollope et al., 1996). Therefore, rather than defining the severity of these fires in terms of long-term vegetation mortality, fire severity in such environments is perhaps better described by process-based functions related to the energy released during the fire, by the amount of biomass combusted, or by the amount of an important element (e.g. nitrogen) volatilised. Such 'process' measures of fire severity include the duration of fire (Jacoby et al., 1992; Perez \& Moreno, 1998), the maximum temperature the fire attained (Debano et al., 1979), or the 
integration of the fire temperature with time (Molina \& Llinares, 2001; Stronach \& McNaughton, 1989; Ventura et al., 1998). In this paper we investigate each of these methods and relate them to surface spectral reflectance of the fires combustion products.

\section{Study area and methodology}

\subsection{Study area}

The study was carried out within Chobe National Park (CNP), northern Botswana. CNP lies within an ecologically diverse region at the transition between the arid/nutrient-rich savannahs of the central Kalahari and the moist/nutrientpoor savannahs of northern Zambia (Huntley \& Walker, 1982; Kamuhuza et al., 1997). Soils at the study site consisted of red Kalahari sands and grey/brown sandy soils. Mean annual precipitation in Chobe is $650 \mathrm{~mm}$, and rainfall occurs predominantly between November and June, with the fire season occurring during the remaining months. During October, when the experiment was performed, monthly mean minimum and maximum temperatures are 6 and $35^{\circ} \mathrm{C}$ respectively. Nine experimental fire plots, each covering $5 \times 5 \mathrm{~m}^{2}$, were burned within $\mathrm{CNP}$ at the end of the 2001 dry season (16th-22nd October 2001) (Fig. 1).
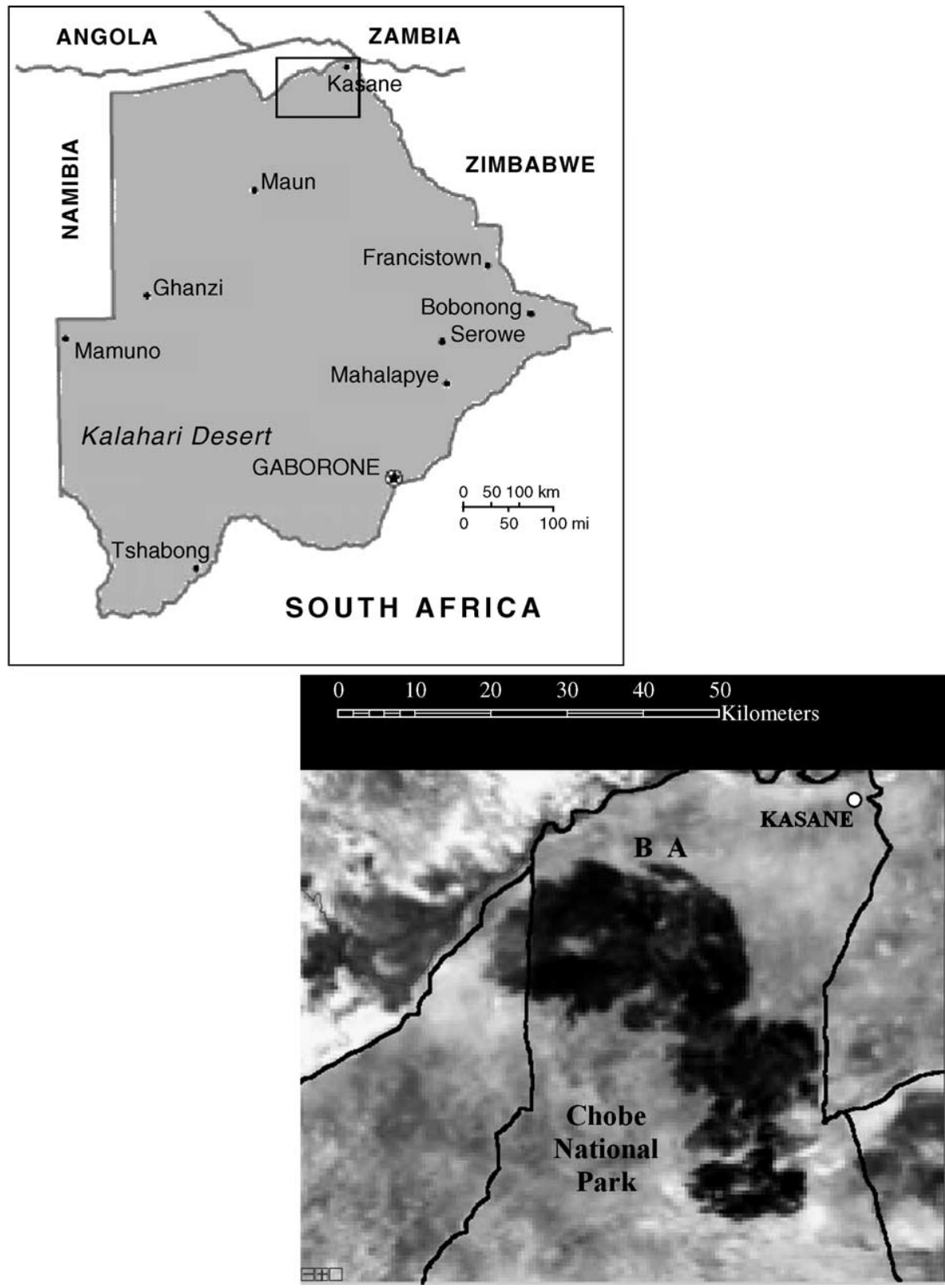

Fig. 1. Location of the study sites in Chobe National Park, northern Botswana. A MODIS near infrared image subset of the area, acquired on 29 September 2001 and overlain with the northeastern park boundary, shows a recent burn as a low albedo area. This indicates the large size of the fires occurring annually in this environment. The experimental fire plots (five at location A and four at location B) were conducted alongside this burn scar. 
Experimental fire plots consisted of light-moderate woodland savannah. The grass species of Dactyloctenium giganteum, Eragrostis lehmanntana, Brachiaria nigropedota, Panicum maximum and Aristida stipitala were present and grass swards contained only senesced biomass and leaf litter, with the grass height typically less than $0.5 \mathrm{~m}$. Grass orientation lay away from the vertical due to the senesced nature of the biomass and excessive trampling by animals. Three tree species were present, Baikiaea plurijuga Fabaceae-Caesalpinioideae (nutrient-poor/deciduous), Combretum spp., and the shrub/tree species Combretum apiculatum. The leaf litter within the experimental plots was predominately from Combretum apiculatum (Smith et al., 2005).

\subsection{Experimental design}

Design of the experimental fire plots was based on that of Stronach and McNaughton (1989), though with a larger plot size and an increased number of inter-plot locations where fire temperatures were measured. Each of the nine plots contained five metal stands arranged in a 'cross' formation (Fig. 2). Three K-type thermocouples (linked to data loggers) were attached to the metal stands at the top, middle and bottom of the grass sward to allow continuous measurement of fire temperature every $0.5 \mathrm{~s}$ throughout the fires duration.

Fires in all the plots were carried out between 9 am and 3 pm local time, and the wind direction was predominantly easterly with low speed $\left(<2 \mathrm{~ms}^{-1}\right)$. Fires were lit at the upwind side of the plot and left to burn. Data from the thermocouples were used to calculate the fire severity measures of fire duration (dt), maximum fire temperature $\left(T_{\max }\right)$, and integrated temperature with time $\left(T_{\text {sum }}\right)$ at each of the five stand locations and three measurement heights. The mean of each measure was also calculated over the three measurement heights at each stand.

\subsection{Calculation of fire characteristic measures}

Fire duration (or residence time) at a particular stand thermocouple is defined as:

$d t=t_{0}-t_{1}$

where $t_{0}$ and $t_{1}$ are, respectively, the time the fire reaches and departs the thermocouple location (seconds). $t_{0}$ is defined as the time at which the temperature increased by greater than $5 \%$ of the previously measured value, while $t_{1}$ is defined as the time at which the temperature decreased to within $5 \%$ of the ambient air temperature and did not increase again above this value.

Maximum fire temperature is the maximum recorded at a particular stand thermocouple, while the integrated temperature for each thermocouple location is calculated as:

$T_{\text {sum }}=\int_{t_{0}}^{t_{1}} T d t$
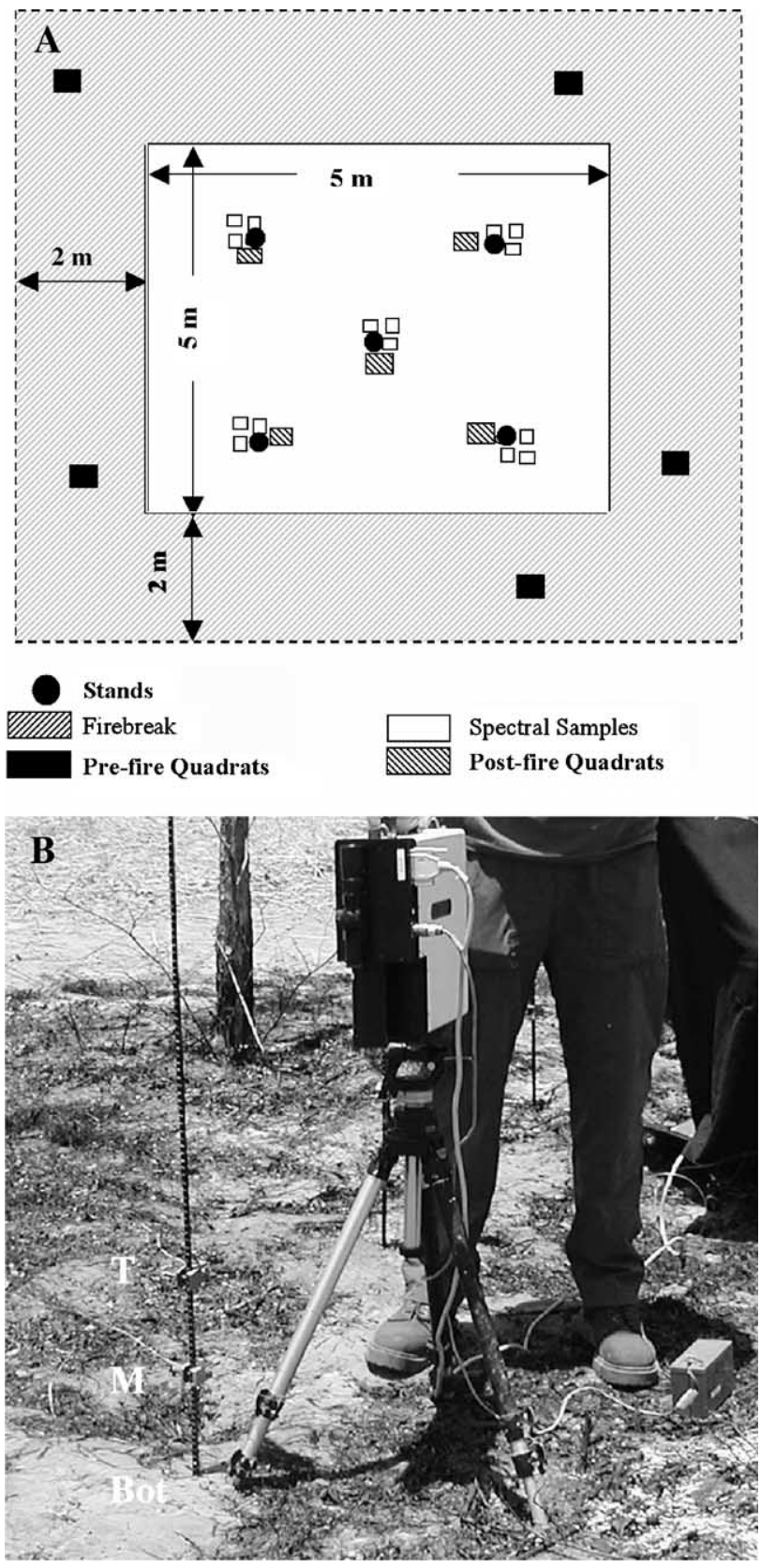

Fig. 2. (A) Arrangement of the experimental fire plots. (B) Example showing the measurement of post-fire surface spectral reflectance adjacent to one of the five thermocouple stands within an experimental fire plot. The locations of the top (T), middle (M), and bottom (Bot) thermocouples are marked.

where, $T$ is the instantaneous fire temperature $\left({ }^{\circ} \mathrm{C}\right)$ and $\mathrm{dt}$ is time (seconds).

Examples of these data from one thermocouple stand are shown in Fig. 3.

Fire line intensity (FLI), which has consistently been used to describe the intensity of experimental fires in southern African savannahs (Hoffa et al., 1999; Trollope et al., 1996), was also calculated from the rate of spread of the fire front deduced from the thermocouple data:

$\mathrm{FLI}=H w r$ 
where FLI is the fire intensity $\left(\mathrm{kJ} \mathrm{s}^{-1} \mathrm{~m}^{-1}\right), H$ is the fuel heat yield $\left(\mathrm{kJ} \mathrm{kg}^{-1}\right), w$ is the mass of dry fuel combusted $\left(\mathrm{kg} \mathrm{m}^{-2}\right.$ ), and $r$ is the rate of spread of the fire front ( $\mathrm{m}$ $\mathrm{s}^{-1}$ ). The heat yield of savannah fuels varies little, and the mean value of $H=16,890 \mathrm{~kJ} \mathrm{~kg}^{-1}$ (Trollope, 1984), appropriate for head fires within a variety of southern African grasses, was used since only head fires were conducted in the experiment. Rate of spread was determined via calculation of the time taken for the fire front to travel between two adjacent thermocouple stands. The mass of fuel combusted was calculated by differencing samples of the pre-fire (fuel) and post-fire (ash and unburned fuel) surface components, as described in the next section.

\subsection{Sampling pre- and post-fire fuel characteristics}

The available fuel load within each experimental plot was estimated using a similar methodology to Shea et al. (1996). Fuel was defined as the total quantity of non-tree aboveground biomass less than $1 \mathrm{~m}$ in height available for combustion. Prior to the fires, sampling of the study area revealed four component categories of surface materials that could act as fuel; senesced grasses (no live grasses were present at this time of the dry season), leaf litter (all leaves on ground), woody litter (fallen twigs, bark pieces and fallen branches $<5 \mathrm{~kg}$ ), and undefined litter (seed pods, burrs, animal dung, ash from previous fires and small unrecognisable pieces of biomass less than $\sim 5 \mathrm{~mm}$ in diameter).

Pre-fire fuel loads in each plot were determined by clipping the biomass within five $0.25 \times 0.25 \mathrm{~m}$ quadrants to the soil level. Quadrant locations were randomly selected from within the $2 \mathrm{~m}$ wide firebreak surrounding each experimental plot, and each sample was separated into the four component categories listed above. The percentage moisture content (\%MC) of each category was measured by weighing samples before and after oven drying for $14 \mathrm{~h}$ at $70{ }^{\circ} \mathrm{C}$. At three of the nine experimental fire plots, additional biomass from the firebreaks and immediate surroundings was uniformly distributed within the plots to replicate the $24,000 \mathrm{~kg} \mathrm{ha}^{-1}$ maximum potential grassland fuel loads observed within CNP, but not present naturally at the time and location of the experiment.

Post-fire surface materials were divided into four categories (charred grass, charred leaf, charred woody materials, and ash of varying shades). The mass per unit area of these materials was sampled via a quadrant placed directly beside the base of each of the five thermocouple stands within each plot, with each sample then being separated into its four constituent components. The $\% \mathrm{MC}$ of each component was again calculated.

The carbon and nitrogen content of each of the pre- and post-fire surface component categories was determined using a NCS2500 CHNS analyser. One 5-g sample of each of pre-fire fuel components for each experimental site was analysed, along with 5-g samples of each post-fire component collected beside each individual thermocouple stand. These data were used, along with the above assessments of the pre- and post-fire surface component masses, to estimate the total amount of carbon and nitrogen volatised (i.e. emitted into the atmosphere) around each stand location.

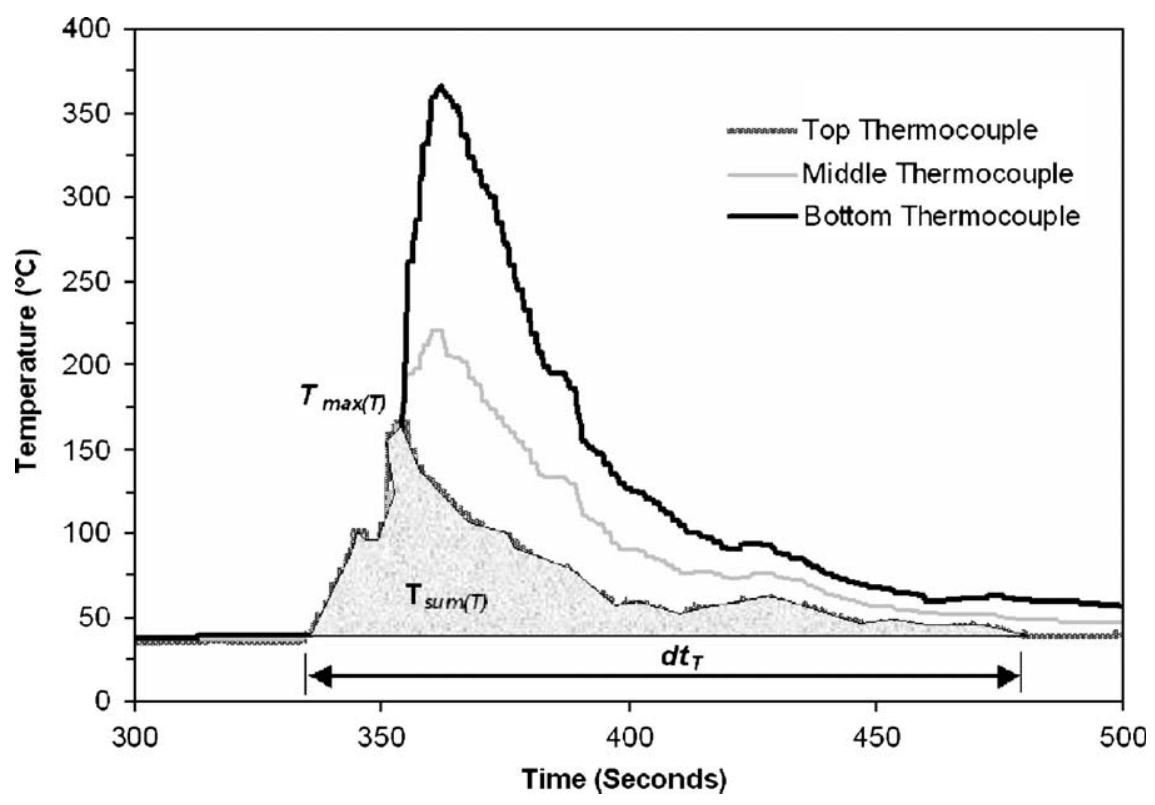

Fig. 3. Example data from one thermocouple stand (holding three thermocouples at the top, middle and bottom of the grass sward) collected during an experimental burn. Measurements made using data from the top thermocouple are indicated, namely fire duration ( $\left.\mathrm{dt}_{\mathrm{T}}\right)$, integrated temperature $T_{\text {sum }}(T)$, and the maximum fire temperature, $T_{\max }(T)$. The equivalent measures are also derived from the middle and bottom thermocouples but are not shown here to aid figure clarity. 


\subsection{Measurement of post-fire surface spectral reflectance}

Post-fire spectral reflectance measurements were made beside each thermocouple stand using a GER 3700 field spectroradiometer immediately after each experimental burn was complete. In addition pre- and post-fire spectra were collected at locations where the individual surface components filled the instrument FOV in order to characterise the spectral reflectance of both ash and fuel endmembers.

The GER 3700 makes 3-degree FOV observations in the $300-2500 \mathrm{~nm}$ spectral range, at a resolution of $1.5-9.5 \mathrm{~nm}$. During measurements, the GER 3700 was held stationary on a tripod at a height of $0.75 \mathrm{~m}$ to acquire spectral measurements at nadir. In order to improve signal to noise, spectral data were calculated as the mean of eight individual spectra taken over a $5 \mathrm{~s}$ interval. Three such measurements were taken at the base of each thermocouple stand, with the instrument field of view (FOV) moved by a few centimetres between each measurement to allow for sampling of smallscale reflectance variations. Spectral observations of a high albedo 'spectralon' reflectance panel were made immediately after each observation of the surface. Post-processing by proprietary software was used to interpolate the raw spectral data to a wavelength interval of $1 \mathrm{~nm}$, and to convert the data to units of surface spectral reflectance via ratioing of the sample spectra against the data from the corresponding spectralon panel observation.

Surface spectral reflectance data were additionally convolved with the spectral response functions of the Landsat Thematic Mapper (TM) and Enhanced Thematic Mapper (ETM+) instruments following the methodology of Trigg and Flasse (2001). Although such simulated ETM+ spectral reflectance measurements do not take into account the effect of the perturbing atmosphere between the land surface and the actual ETM+ sensor, and are at a widely differing spatial resolution to the true ETM+ observations, the convolved data do provide an indication of the spectral sampling capabilities of the ETM+ with respect to the individual surface components.

The simulated ETM+ spectral reflectance observations were used to assess the utility of Landsat-type Earth Observation imagery for fire severity mapping, and were also used to evaluate the utility of the Normalised Burn Ratio (NBR), proposed by Key and Benson (2002) as a remotely sensed measure of fire severity:

$\operatorname{NBR}=\left(\rho_{4}-\rho_{7}\right) /\left(\rho_{4}+\rho_{7}\right)$

where $\rho_{4}$ and $\rho_{7}$ are the surface spectral reflectances measured in bands $4(0.76-0.90 \mu \mathrm{m})$ and $7(2.08-2.35$ $\mu \mathrm{m})$ of the ETM+ sensor. The NBR was developed primarily for use in the western United States, and is based on the principal that burning lowers surface NIR reflectance and raises mid-infrared reflectance compared to pre-fire conditions (van Wagtendonk et al., 2004). Similar surface spectral reflectance changes occur for savannah fires in southern Africa (Eva \& Lambin, 1998; Trigg \& Flasse, 2000).

\subsection{Assessing the spectral mixing properties of ash mixtures}

In order to further our understanding of ash spectral reflectance and how it varies from the scale of the field experiment to that of the satellite sensor, optical mixing experiments involving differing proportions of white and black ash were conducted in the laboratory. The most appropriate spectral mixture models were then applied to airborne and simulated satellite observations to evaluate the different sensors ability to detect white ash deposits, which are a basic signifier of higher intensity fires.

Pure samples of white and black ash were collected in the field for later laboratory analysis. The black and white ash samples were dry sieved through successive 1600, 300, 75, and $50 \mu \mathrm{m}$ sieves to determine the proportion by weight of each grain size class. The spectral reflectance of each class was measured in the laboratory using the GER 3700 spectroradiometer with a ground FOV diameter of $7.8 \mathrm{~cm}$. Illumination was provided by a $1000 \mathrm{~W}$ video lamp, positioned at alternating incidence angles of nadir and $\sim 45^{\circ}$.

Only the $50-75 \mu \mathrm{m}$ particle size class was present in sufficient quantity for the next stage of the experiment. To model linear mixing of the black and white ash samples, samples of the $50-75 \mu \mathrm{m}$ particle size class of each ash type were arranged in a checkerboard pattern, so that each ash type covered an equivalent percentage area (i.e. 50\%). This allowed representation of the 'classic' optical linear mixing scenario whereby the vast majority of photons reflect only off one surface component before being measured by the sensor (Settle \& Drake, 1993). The size of the checkerboard squares was 3.7 by $4.4 \mathrm{~cm}$, with an approximate ash layer thickness of $0.9 \mathrm{~cm}$. Between each spectral reflectance measurement the checkerboard arrangement was rotated about a point (taken as the intersection location of neighbouring 4 squares), and in total forty individual measurements were collected at random orientations. The mean spectral reflectance of the observations was then calculated. For comparison, the reflectance spectrum of the checkerboard arrangement was modelled as the area weighted sum of the individual black and white ash spectral endmembers:

Checkerboard Spectrum $=\frac{1}{2}\left(S_{\mathrm{B}}+S_{\mathrm{W}}\right)$

where $S_{\mathrm{B}}$ and $S_{\mathrm{W}}$ are the spectral reflectance curves of black and white ash, respectively. The modelled reflectance spectrum was then compared to the observed reflectance spectrum in order to assess the validity of the assumption of linear mixing when analysing and modelling observations of the combustion products laid down on post-fire surfaces.

Following the above process, the 50\% black and 50\% white ash used in the checkerboard distribution were mixed 
completely, and were then re-deposited on the surface as an intimate mixture rather than the previous checkerboard arrangement. This allowed evaluation of a non-linear mixing scenario in which photons interact with (i.e. are scattered by) multiple surface components before being detected by the sensor (Borel \& Gerstl, 1994; Foody et al. 1997). Following Clark (1983), Johnson et al. (1983, 1992), and Hapke (1993) we modelled the reflectance spectrum of intimate binary mixtures that consist of isotropic scatterers larger than the wavelength by application of the single scattering albedo (w) approximation (Hapke, 1993):

$w=\frac{w_{\mathrm{wh}}+\varepsilon w_{\mathrm{b}}}{1+\varepsilon}$

where wh denotes white ash, $\mathrm{b}$ denotes black ash, and the parameter $\varepsilon$ is given by:

$\varepsilon=\frac{M_{\mathrm{wh}}}{M_{\mathrm{b}}} \cdot \frac{\rho_{\mathrm{b}}}{\rho_{\mathrm{wh}}} \cdot \frac{D_{\mathrm{b}}}{D_{\mathrm{wh}}}$

where $M$ is the bulk density (approximated by weighing the quantity of ash to fill a known volume within a test-tube); $\rho$ is the solid density and $D$ is the diameter of the particles. Following Hapke (1993) we assume that $\rho_{\mathrm{b}}$ and $\rho_{\mathrm{wh}}$ are equal.

Using the above approximation, and assuming that the mixture contains isotropic scatterers with negligible opposition effect, $w$ is given by (Hapke 1993):

$w=1-\gamma^{2}$.

The parameter $\gamma$ of the combined mixture can then be obtained using (Hapke 1993):

$\gamma(\Gamma)=\frac{\left\lfloor\left(\mu_{0}+\mu\right)^{2} \Gamma^{2}+\left(1+4 \mu_{0} \mu \Gamma\right)(1-\Gamma)\right\rfloor^{1 / 2}-\left(\mu_{0}+\mu\right) \Gamma}{1+4 \mu_{0} \mu \Gamma}$

$\Gamma\left(\mu_{0}, \mu, g\right)=\frac{1-\gamma^{2}}{\left(1+2 \gamma \mu_{0}\right)(1+2 \gamma \mu)}$

where, $\mu_{0}=\cos (e)$ and $\mu=\cos (i), i$ and $e$ denote the angles of incidence and reflection respectively, $\Gamma$ represents the bidirectional reflectance, and $g$ is the phase angle.

Field observations of the patch size and spatial distribution of white ash produced in natural fires showed that white ash can be found in much larger patches than those employed in the laboratory or field experiments. To assess the wider spatial distribution of black and white ash deposits in natural fires occurring in and around CNP we used true color digital aerial photography $(120 \times 60 \mathrm{~m}$; Fig. 11B), acquired at an approximate spatial resolution of $30 \mathrm{~cm}$ (Smith \& Hudak, in press). The highest density of white ash was identified $90 \mathrm{~km}$ northeast of the study area, over burned savannah woodland in northwestern Zimbabwe on 19th October 2001. The areal percentage of white ash in this area was calculated from the photography using a region segmentation algorithm based on simple DN thresholding.

\section{Results and discussion}

\subsection{Fuel characteristics at the experimental fire plots}

The fuel moisture content was found to be low, ranging from $3 \%$ to $12 \%$ across all fuel components. This is a result of the parched conditions at the end of the dry season. Natural pre-fire fuel loads varied between 2000 and $9930 \mathrm{~kg} \mathrm{ha}^{-1}$, while the artificially loaded plots varied between 13,871 and $24,000 \mathrm{~kg} \mathrm{ha}^{-1}$. Grass accounted for the largest proportion ( $47 \pm 27 \%$ ) of the pre-fire fuel mass, followed by woody litter, undefined litter, and leaf litter, each of which was present in similar proportions by weight $(20 \pm 20 \%, 19 \pm 17 \%, 14 \pm 9 \%$ respectively). Total biomass combusted ranged between 869 and $19,316 \mathrm{~kg} \mathrm{ha}^{-1}$. Post-fire fuel components consisted mainly of ash $(51 \pm 23 \%)$ and charred woody materials $(24 \pm 23 \%)$, with lesser amounts of charred grass and leaf materials $(10 \pm 9 \%$ and $15 \pm 10 \%$ respectively). These data suggest that the experimental fires were mainly supported by the grass component of the fuel, and that leaf and woody litter burned far less readily. This was also observed to be the case in natural fires adjacent to the experimental sites, though it was also apparent that entire dead trees and fallen branches had occasionally combusted completely to white mineral ash in neighbouring wildfire events.

Measurement of the pre- and post-fire nitrogen and carbon contents (Table 1), in addition to the calculated biomass combusted, enabled calculation of the emission factors $\left(\mathrm{EF}_{X}=\right.$ the quantity of gas $X$ emitted in grams per kilogram of dry matter combusted) of carbon and nitrogen (Andreae \& Merlet, 2001). As 'emission factors' typically refer to the emission of gas species, rather than the emission of an element, we hereafter refer to the 'elemental emission factor' of carbon and nitrogen respectively. The elemental emission factor of carbon was effectively constant $\left(\mathrm{EF}_{\mathrm{C}}=491 \pm 7.5 \mathrm{~g} \mathrm{~kg}^{-1}, r^{2}=0.99, n=36, p<0.001\right)$ and as such, the relationships presented in this paper that predict biomass combusted can effectively be applied to obtain a direct estimate of carbon volatilised. However, the elemental emission factor of nitrogen was more variable $\left(\mathrm{EF}_{\mathrm{N}}=\right.$

Table 1

Percent by weight nitrogen and carbon contents of pre- and post-fire components

\begin{tabular}{|c|c|c|c|c|c|c|c|c|}
\hline \multicolumn{9}{|l|}{ Pre-fire } \\
\hline \multicolumn{5}{|c|}{$\%$ Nitrogen content } & \multicolumn{4}{|c|}{$\%$ Carbon content } \\
\hline & Grass & Leaf & Wood & & Grass & Leaf & Wood & \\
\hline Mean & 0.76 & 1.22 & 0.90 & & 43.79 & 49.19 & 47.03 & \\
\hline St. dev. & 0.25 & 0.11 & 0.20 & & 2.62 & 1.34 & 1.34 & \\
\hline \multicolumn{9}{|l|}{ Post-fire } \\
\hline \multicolumn{5}{|c|}{$\%$ Nitrogen content } & \multicolumn{4}{|c|}{$\%$ Carbon content } \\
\hline & Grass & Leaf & Wood & Ash & Grass & Leaf & Wood & Ash \\
\hline Mean & 0.93 & 1.68 & 1.03 & 0.89 & 44.76 & 51.84 & 51.30 & 24.06 \\
\hline St. dev. & 0.26 & 0.28 & 0.61 & 0.38 & 2.19 & 2.23 & 8.53 & 9.16 \\
\hline
\end{tabular}


$\left.9.3 \pm 3.1 \mathrm{~g} \mathrm{~kg}^{-1}, r^{2}=0.88, n=24, p<0.001\right)$, indicating that a direct estimate of nitrogen volatised based on a simple estimate of total biomass combusted will have limited accuracy. The variation of $\mathrm{EF}_{\mathrm{N}}$ is due the range of nitrogen contents within the different fuel components, while the carbon content of vegetation is typically relatively constant between $45 \%$ and 50\% (Levine, 1990).

\subsection{Relationships between fuel and fire characteristics}

Fireline intensity (FLI) for the five naturally loaded fire plots varied between 130 and $9474 \mathrm{~kW} \mathrm{~m}^{-1}$. The maximum is higher than that found in previous studies (e.g. $<4000 \mathrm{~kW}$ $\mathrm{m}^{-1}$ in Trollope et al., 1996) and results from the higher fuel loads used here. In contrast to the other fire characteristic measures listed in Table 2, for which values occupied the entire recorded range, FLI exhibits a more bi-modal distribution where values are clustered in low $(<1000 \mathrm{~kW}$ $\mathrm{m}^{-1}$ ) and high (>5000 $\mathrm{kW} \mathrm{m}^{-1}$ ) FLI groupings (Fig. 4). Linear regressions between FLI and carbon and nitrogen volatised, based on the entire data set as a whole, are included in Table 2 but may present a somewhat biased interpretation since the bimodal nature of the data will tend to produce higher positive correlations than may exist within each separately. Consequently, the data of each FLI group was also analysed individually. No significant relationship existed between FLI and nitrogen volatilised for the FLI $<1000 \mathrm{~kW} \mathrm{~m}^{-1}$ grouping, and within this group the data exhibited very large degree of scatter (Fig. 4A) due to these low intensity burns being supported by different mixes of wood, grass, leaf and other litter which each have widely different percentage nitrogen contents (Table 1). The lower scatter within the FLI $>5000 \mathrm{~kW} \mathrm{~m}^{-1}$ group results from these higher intensity fires being dominated by large amounts of grassy fuel (so fuel nitrogen content was less variable) and within this group a statistically significant relationship was found between FLI and nitrogen volatised $\left(r^{2}=0.50, n=20, p<0.05\right)$. For the relationship between carbon volatised and FLI (Fig. 4B), the data in the FLI $<1000 \mathrm{~kW} \mathrm{~m}^{-1}$ grouping shows less scatter than for nitrogen volatised (Fig. 4A) since wood, grass and leaf litter have very similar \% carbon contents (Table 1 ). However, still no significant relationship existed between carbon volatilised and FLI in this FLI $<1000 \mathrm{~kW} \mathrm{~m}^{-1}$ grouping, but a weak yet statistically significant relationship $\left(r^{2}=0.34\right.$, $n=20, p<0.05)$ was found for the FLI $>5000 \mathrm{~kW} \mathrm{~m}^{-1}$ group.

Statistically significant linear correlations were found between the integration of fire temperature with time $\left(T_{\text {sum }}\right)$, as measured at each individual thermocouple, and total fuel load combusted (Table 2). The strength of these relationships increased with temperature measurement height within the grass sward, agreeing with past findings on fire temperature and height relationships in savannah grass swards (Stronach, 1989; Trollope \& Potgieter, 1985). While the relationship was statistically insignificant for the bottom-of-sward measure, the middle- and top-of-sward $T_{\text {sum }}$ measures were well related to biomass combusted (Middle: $r^{2}=0.89, n=25$, $p<0.001$; Top: $\left.r^{2}=0.91, n=32, p<0.001\right)$. Although a positive linear trend was observed in these regressions, only five $T_{\text {sumT }}$ values exceeded $300{ }^{\circ} \mathrm{C}-$ min. Although not statistically defensible, removal of these points demonstrated that a positive but weaker linear relationship remained between $T_{\text {sumT }}$ and the biomass combusted $\left(r^{2}=0.42\right.$, $n=27, p<0.001)$. Relationships between $T_{\text {sum }}$ and the quantity of nitrogen volatilised were found to be poor (Bottom: $r^{2}=0.24, n=32, p<0.005$; Middle: $r^{2}=0.41$, $n=25, p<0.005$; Top: $\left.r^{2}=0.17, n=32, p=0.011\right)$. Although the mean of the integrated temperature includes the poorly performing bottom thermocouple value, reasonable relationships between this mean and both the biomass combusted (Mean: $r^{2}=0.72, n=25, p<0.001$ ) and nitrogen volatilised (Mean: $r^{2}=0.41, n=25, p<0.005$ ) were found.

No statistically significant relationships $(p<0.2)$ were observed between measures of biomass combusted or nitrogen/carbon volatilised and the maximum temperature

Table 2

Statistically significant relationships between fuel combusted and nitrogen volatilised $(y)$, and measures of fire severity $(x)$

\begin{tabular}{|c|c|c|c|c|c|c|}
\hline$y$ & $\mathrm{x}$ & Equation & $r^{2}$ & $n$ & Sig. ( $p$-value) & SE (model) \\
\hline \multirow[t]{8}{*}{$\mathrm{N}$ volatilised } & FLI & $y=5.10^{-7} x+0.0017$ & 0.74 & 34 & $<0.001$ & 0.0006 \\
\hline & $\mathrm{dt}_{\mathrm{B}}$ & $y=7.10^{-6} x+0.001$ & 0.60 & 32 & $<0.001$ & 0.0015 \\
\hline & $\mathrm{dt}_{M}$ & $y=7.10^{-6}+0.0015$ & 0.53 & 32 & $<0.001$ & 0.0016 \\
\hline & $\mathrm{dt}_{\mathrm{T}}$ & $y=1.10^{-5} x+0.0009$ & 0.73 & 32 & $<0.001$ & 0.0019 \\
\hline & $T_{\text {sumB }}$ & $y=1.8 \cdot 10^{-6} x+3.0 E-03$ & 0.24 & 32 & $<0.005$ & 0.0019 \\
\hline & $T_{\text {sum } M}$ & $y=8.9 \cdot 10^{-6} x+2.12 E-03$ & 0.41 & 25 & $<0.005$ & 0.0018 \\
\hline & $T_{\text {sumT }}$ & $y=0.018 \ln (x)-0.0052$ & 0.17 & 32 & 0.011 & 0.0018 \\
\hline & $T_{\text {sum } \mu}$ & $y=6.77 E-06 x+1.66 E-03$ & 0.41 & 25 & $<0.005$ & 0.0019 \\
\hline \multirow[t]{7}{*}{$\mathrm{C}$ volatilised fuel combusted } & FLI & $y=6.10^{-5} x+0.0537$ & 0.58 & 35 & $<0.001$ & 0.1765 \\
\hline & $T_{\text {sum } M}$ & $y=1.906 x+43.074$ & 0.89 & 25 & $<0.001$ & 0.1742 \\
\hline & $T_{\text {sumT }}$ & $y=2.5384 x+7.0981$ & 0.91 & 32 & $<0.001$ & 0.1807 \\
\hline & $T_{\text {sum } \mu}$ & $y=1.5841 x+106.49$ & 0.72 & 25 & $<0.001$ & 0.2892 \\
\hline & $\mathrm{dt}_{\mathrm{B}}$ & $y=1.0274 x+169.86$ & 0.46 & 32 & $<0.001$ & 0.5153 \\
\hline & $\mathrm{dt}_{M}$ & $y=1.1438 x+135.39$ & 0.63 & 32 & $<0.001$ & 0.4053 \\
\hline & $\mathrm{dt}_{\mathrm{T}}$ & $y=1.8911 x+45.962$ & 0.72 & 32 & $<0.001$ & 0.3403 \\
\hline
\end{tabular}




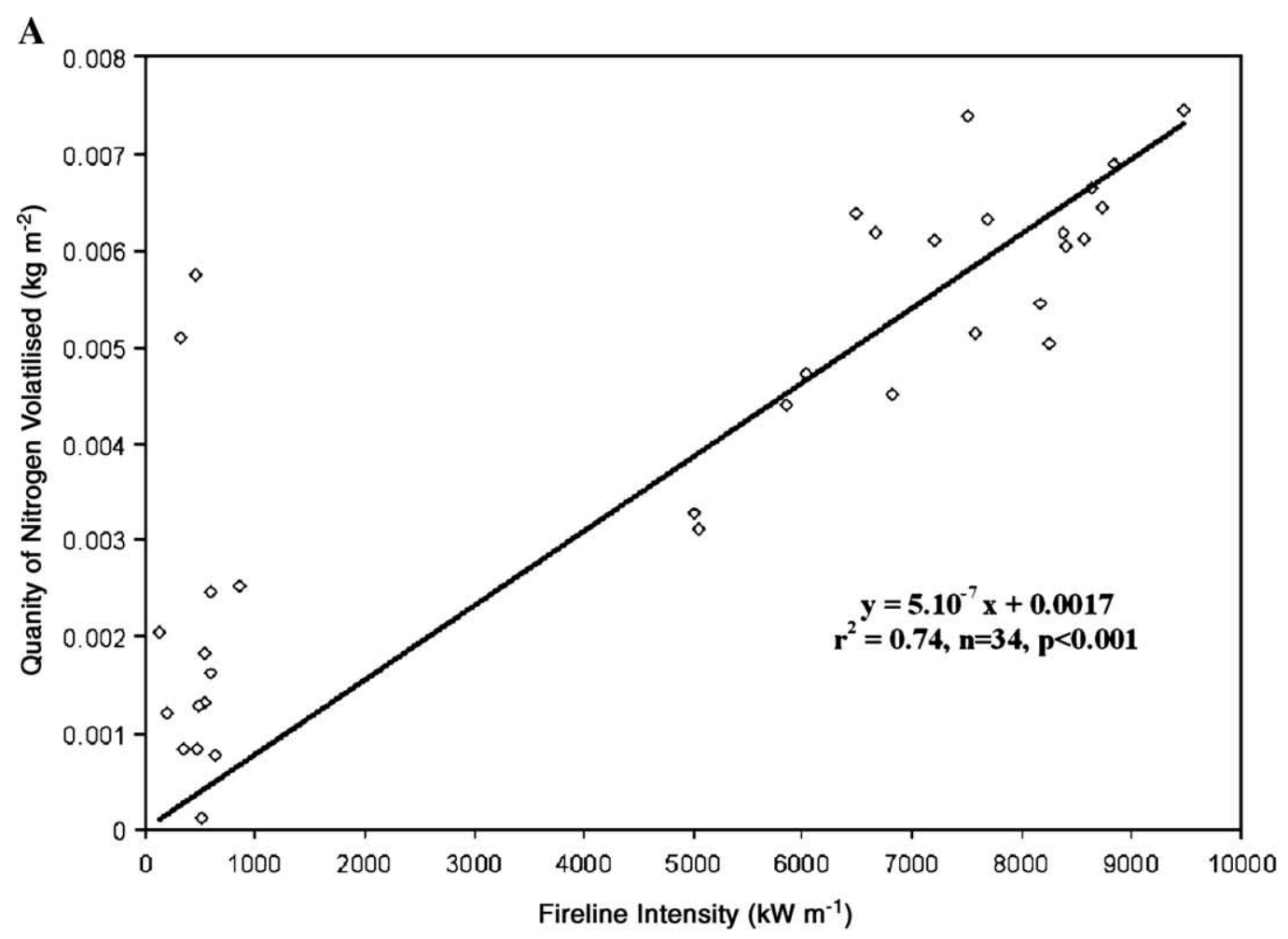

B

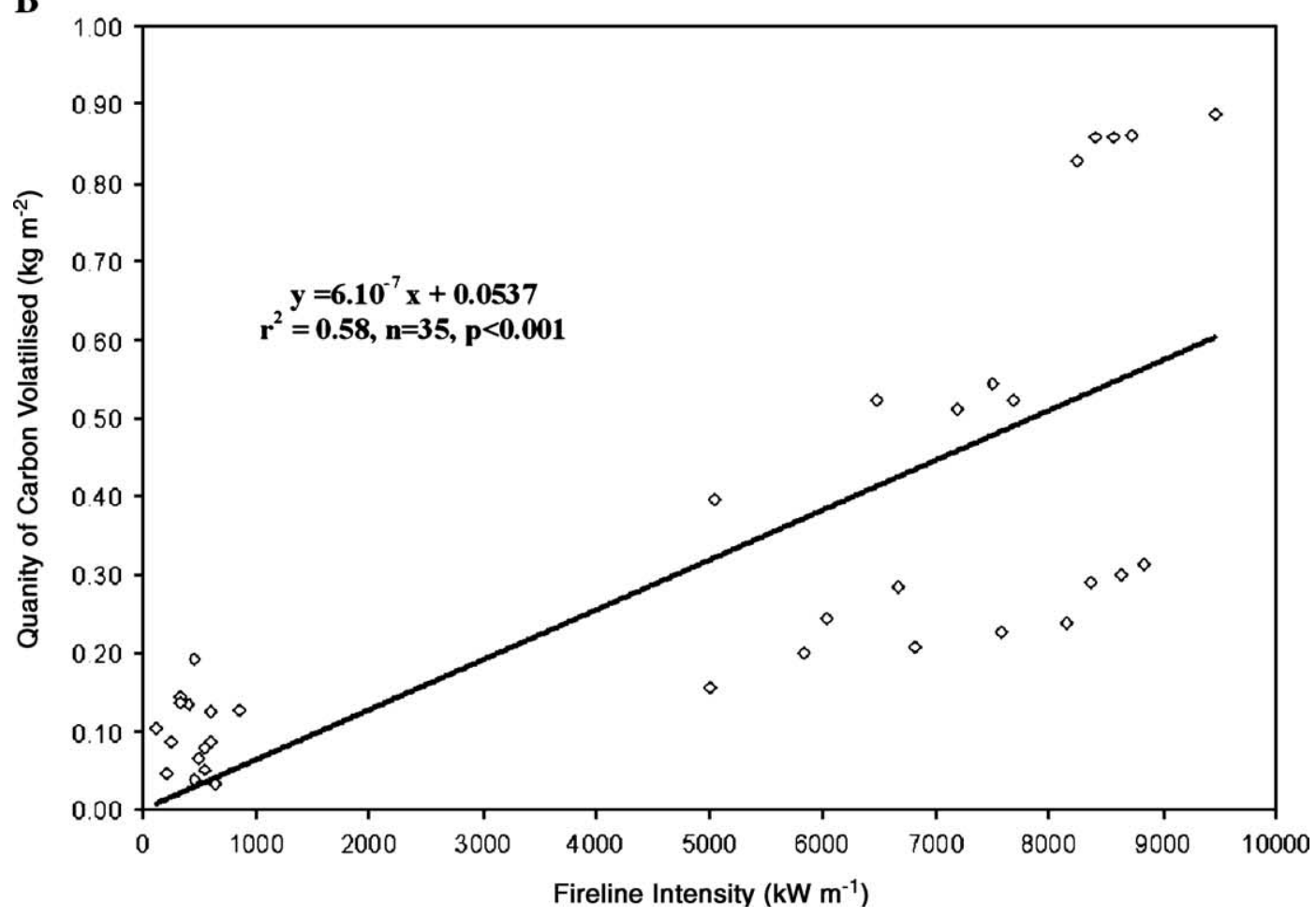

Fig. 4. Relationships between fireline intensity and (A) quantity of nitrogen volatilised, (B) quantity of carbon volatilised.

( $\left.T_{\max }\right)$ obtained at any thermocouple location, regardless of height. However, fire duration (dt) measured at the top thermocouple produced statistically significant linear relationships with both biomass combusted $\left(r^{2}=0.72, n=32\right.$, $p<0.001)$ and nitrogen volatilised $\left(r^{2}=0.73, n=32\right.$, $p<0.001$ ) (Table 2). As observed for $T_{\text {sum }}$, the strength of the relationships between $\mathrm{dt}$ with biomass combusted decreased with measurement height (Bottom: $r^{2}=0.46$, $n=32, p<0.001$; Middle: $\left.r^{2}=0.63, n=32, p<0.001\right)$ and this was also the case for nitrogen volatilised (Bottom: 
$r^{2}=0.60, n=32, p<0.001 ;$ Middle: $r^{2}=0.53, n=32$, $p<0.001$ ).

From these results, it is apparent that the measures of fire duration and integrated temperature with time are relatively well related to the amount of biomass combusted and quantity of nitrogen volatilised. Fireline intensity also relates to the quantity of nitrogen volatilised, but exhibits a statistically less significant relationship than does fire duration. The maximum temperature attained during combustion was found to be poorly related to nitrogen volatilised. This may be because measured temperatures are likely to be strongly related to the exact placement of thermocouples, since flame and fuel characteristics can vary markedly over very small distances (Keane et al. 2001). Displacement of a few centimetres or so in thermocouple location may influence the maximum recorded temperature considerably, whereas the measure of fire duration is likely to be much less affected. This can be seen to some extent in Fig. 3, where greatly differing temperatures are recorded by the three thermocouples but where the top and middle fire duration measures only differ by $4 \mathrm{~s}$.

\subsection{Savannah surface spectral characteristics}

Pre-fire surfaces were characterised by red Kalahari sands, grey/brown soils, senesced grasses, senesced leaf litter, and woody debris. Post-fire surfaces consisted of black ash, white ash, unburned senesced biomass, and bare soil (a certain proportion of which was newly revealed by the combustion of the overlying biomass during the fire). Fig. 5 shows the field reflectance spectra of each the individual pre- and post-fire surface components. Pre-fire components have the potential to act as fuel, while post-fire components include combustion products and underlying soils, which will have the same post-fire locations but whose cover might change due to the deposition of combustion products and the removal of vegetation through combustion (Fig. 5).

Within the pre-fire spectra (Fig. 5A), spectral differences between the green leaves and dead grass and leaves is due to vegetation senescence. As plants senesce and dry, losses of water and chlorophyll result in the removal of absorption features associated with these compounds, and their replacement by absorption features due to lignin and cellulose that comprises the majority of the senesced material (Fig. 5A; Asner, 1998; Elvidge, 1990). Wood is seen to exhibit a similar spectral reflectance pattern to senesced vegetation, since it is composed of somewhat similar materials (Fig. 5A).

The spectral reflectance of the post-fire surface components contrasts strongly with that of the pre-fire counterparts (Fig. 5B). Black ash has a very low spectral reflectance, and is spectrally featureless in terms of notable absorption features, apart from an apparent reflectance peak around $2.35 \mu \mathrm{m}$. This is very likely due to radiative emission from the still hot ash at wavelengths longer than around $2.3 \mu \mathrm{m}$, coupled with water vapour absorption effects at $2.4 \mu \mathrm{m}$ and longer wavelengths. Section 4.6 will confirm that laboratory re-measurement of the black ash spectra (once fully cooled) fails to show this feature.

White ash exhibits a significantly higher reflectance than does black ash, right across the $0.3-2.5 \mu \mathrm{m}$ spectral range, and the spectral reflectance of white ash increases in a linear fashion by around $10-20 \%$ over the $0.3-2.5 \mu \mathrm{m}$ range. At wavelengths greater than $2.3 \mu \mathrm{m}$ the spectral reflectance of the white ash increases more steeply, again presumably also due to the radiative emission of the still hot ash. For the in situ white ash spectra, no spectral reflectance decrease beyond $2.4 \mu \mathrm{m}$ is seen (Fig. 5B). Since white ash is produced at the highest intensity parts of a fire, at a set after the fire white ash surfaces are likely to be somewhat hotter than the black ash surfaces. During the experiment, ash surface temperatures were noted to exceed $100{ }^{\circ} \mathrm{C}$ as measured by a thermal infrared thermometer. Therefore, the contribution of short wavelength radiant energy emission to the overall spectral measurement may typically be greater for white ash than for black ash (assuming they have not yet cooled to ambient) and maybe enough to fully counter the effects of water vapour absorption on the composite signal at wavelengths longer than $2.4 \mu \mathrm{m}$. The $0.3-2.5 \mu \mathrm{m}$ spectral reflectance observations of ash measured in situ on burned savannah surfaces by Trigg and Flasse (2000) and Landmann (2003) are similar to those noted here.

The assumption of thermal emission being responsible for certain of the shortwave infrared spectral reflectance features discussed above can be easily assessed using values of incoming solar spectral irradiance and an assumed typical post-fire surface lambertian spectral reflectance of $\sim 20 \%$ (Fig. 5B). Rearrangement of Planck's radiation law with an assumed ash surface temperature of $100{ }^{\circ} \mathrm{C}$ indicates that the additional thermally emitted spectral radiance would be sufficient to increase the apparent surface spectral reflectance by $\sim 10 \%$, which is in fact around the noted magnitude of the effect. More time would have permitted the post-fire surface to cool further before measurement, however wind can rapidly remove a certain proportion of ash post-fire, and to guard against this possibility rapid post-fire spectral measurement was necessary.

Soils spectra differed significantly from those of vegetation and ash. Each soil exhibited a characteristic spectral absorption feature at $2.2 \mu \mathrm{m}$, associated with the hydroxyl bond (Nagler et al., 2000). However, soil reflectances differed in the visible and NIR. Red soils showed spectral features suggesting the presence of iron oxides, whilst grey/ brown soils showed features suggesting a high organic carbon content (Huete \& Escadafal, 1991; Nagler et al., 2000).

In contrast to the 'endmember' spectra of the individual surface components shown in Fig. 5, most of the in situ 


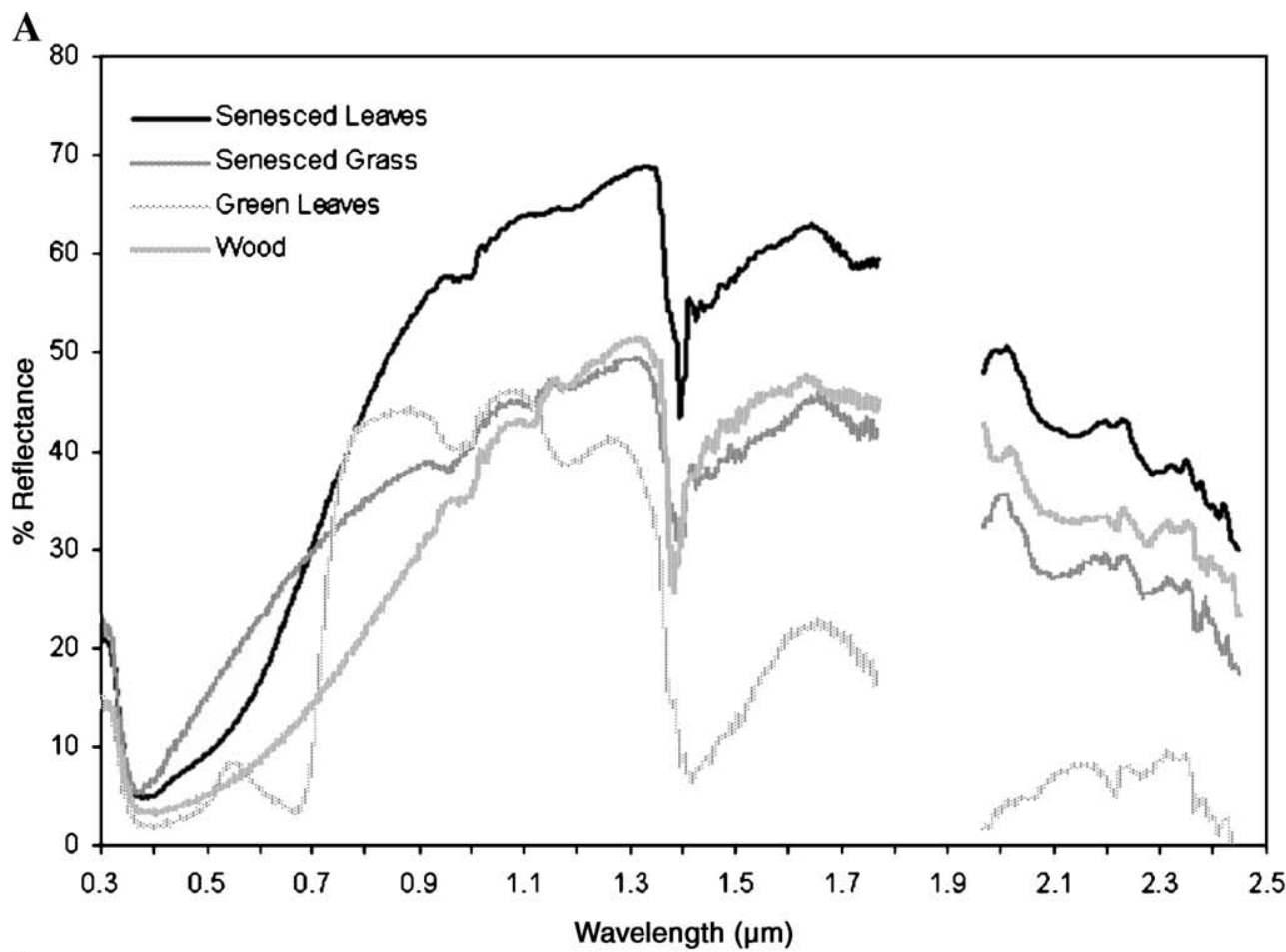

B

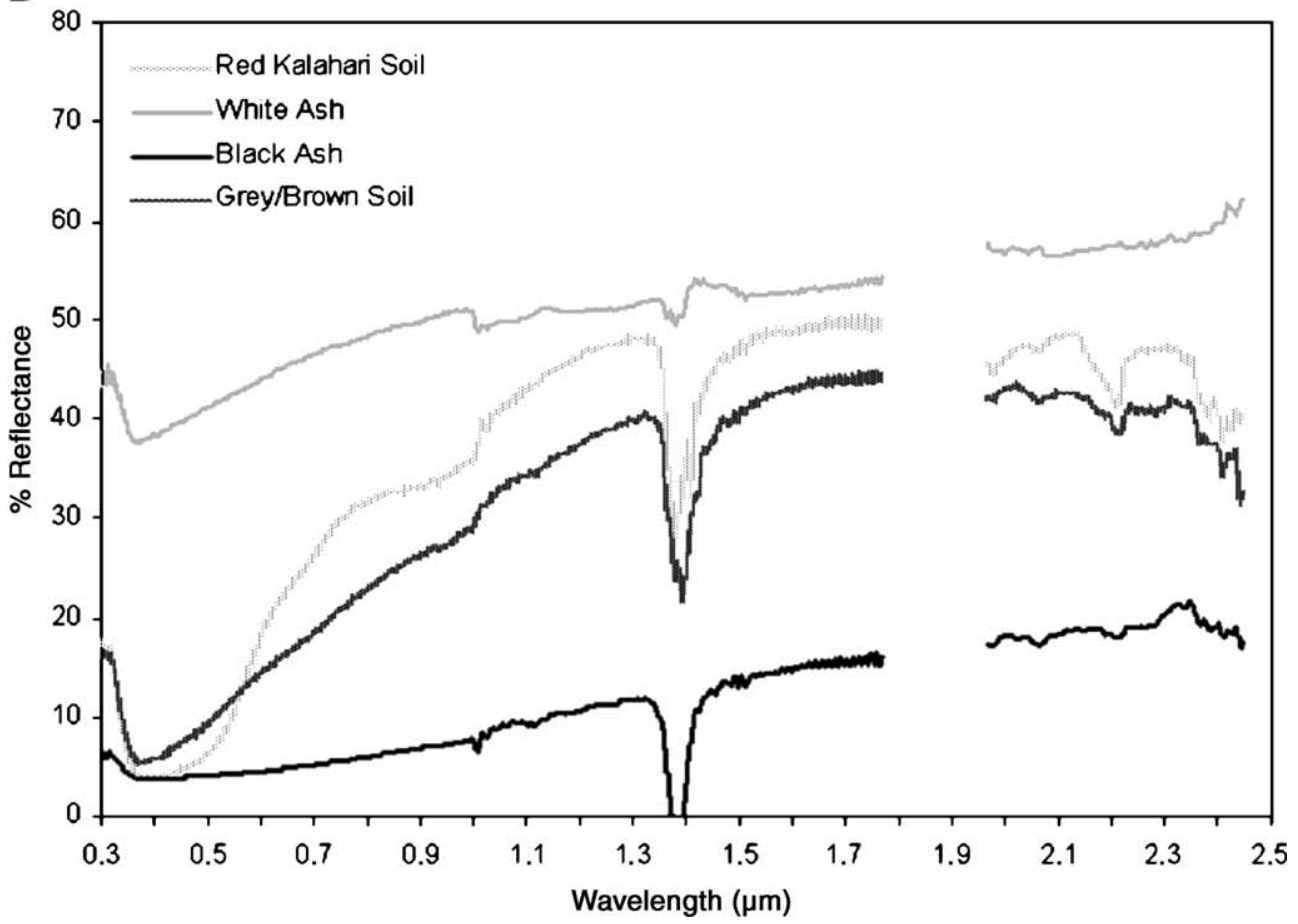

Fig. 5. Spectral reflectance of the individual sample components found at the field site. (A) Spectral reflectance of the pre-fire components with the potential to act as fuel. (B) Spectral reflectance of the post-fire components (i.e. ash derived from burning of the fuel) and also of the underlying sand and soil whose percentage cover can change due to vegetation combustion and ash deposition. Spectral reflectance measures between 1.8 and $1.9 \mu$ mere strongly affected by atmospheric water absorption and were excluded in these plots. Water absorption also affected measurements around 1.4 and $>2.4 \mu \mathrm{m}$, but was somewhat less severe.

spectral observations at the measurement stand locations were in fact mixtures of bare soil, unburned vegetation and ash, each with varying percentage covers. This mixing is reflected in the spectral data at these sites, an example of which is shown in Fig. 6, which demonstrates that a given surface reflectance can be approximated by a linear combination of the black and white ash end-member spectra. 


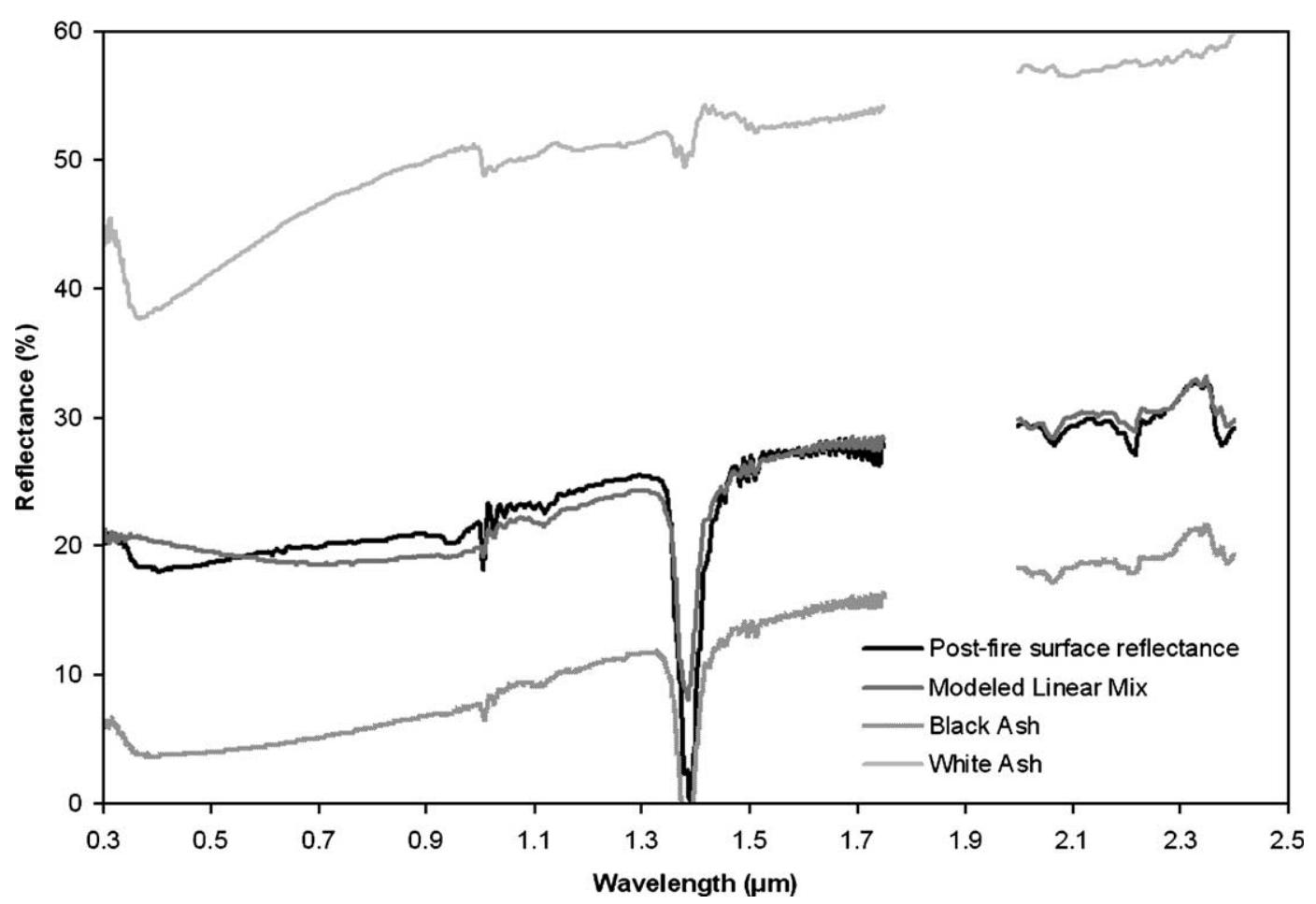

Fig. 6. Comparison between a simulated linear mix of black ash and white ash spectra (unknown proportion) to actual field-measured spectra. The coefficient of determination between the simulated and real spectra over all wavelengths is $r^{2}=0.91$, indicating the linear mixing model provides a reasonable fit to the measured spectra.

\subsection{Relationships between fire characteristics and surface spectral reflectance}

No statistically significant relationships were found between post-fire surface spectral reflectance and biomass combusted or carbon/ nitrogen volatilised, nor between reflectance and maximum fire temperature $\left(T_{\max }\right)$ or fireline intensity. However, statistically significant relationships were found between post-fire surface spectral reflectance and integrated fire temperature $\left(T_{\text {sum }}\right)$ and fire duration $(\mathrm{dt})$. The best-fit relationships were quadratic in nature, with two clear regimes corresponding to low and high severity/ duration. The fire duration as measured by the top thermocouple $\left(\mathrm{dt}_{\mathrm{T}}\right)$ exhibited less scatter and a more pronounced threshold between the two regimes than did the mean of the integrated temperature measured at the same location $\left(T_{\text {sum } \mu}\right)$ (Fig. 7A,B), or the other measures of fire duration and integrated temperature. Therefore, the analysis hereafter only considers fire duration as measured by the top thermocouple $\left(\mathrm{dt}_{\mathrm{T}}\right)$, as opposed to that measured at the lower thermocouple locations. Although, the quadratic nature of the relationship was observed at all wavelengths, the curvature of the quadratic relating $\mathrm{dt}_{\mathrm{T}}$ and spectral reflectance was more pronounced at longer wavelengths (Fig. 8A,B). For each wavelength examined, the degree of reflectance variation for any particular fire duration measure was much greater for shorter durations than longer ones (Fig. 8A). This was repeated when the reflectances were convolved to the ETM+ response functions (Fig. 8B). These findings can perhaps best be understood through the mechanism of two fire duration regimes (separated by a duration threshold), in which a variety of mixing processes were acting.

\subsubsection{Low fire severity/duration regime}

Lower severity fires burnt smaller quantities of fuel, primarily on the plots having the lowest fuel loads. In such fires, only a limited amount of ash was produced, and it was common that only a proportion of the post-fire surface was covered by ash, with the remainder of the surface being exposed bare soil and/or unburned fuel. In such fires, the spectral reflectance of the post-fire surface is significantly influenced by both the proportion of exposed soil and by the amount of unburned fuel remaining. In this savannah environment, soils exhibit a variety of spectral reflectances (Fig. 5). This is in contrast to unburned fuel, which is dominated by senesced grass having a relatively high spectral reflectance (Fig. 5A). During fires, as an increasing quantity of fuel is combusted, more soil may be revealed. As an increasing quantity of fuel is combusted within a fire it is likely that more of the underlying soil is revealed, however this soil can also be increasingly masked by the laying down of greater amounts of ash on the surface. In low severity fires, this ash is only partly combusted and has the typically low spectral reflectance of black ash, char or charcoal (Fig. 5B; Robinson, 1991; Trigg \& Flasse, 2000). The overall mix of black ash, soils and unburned fuel, at different proportions and with differing spectral reflectances, results 


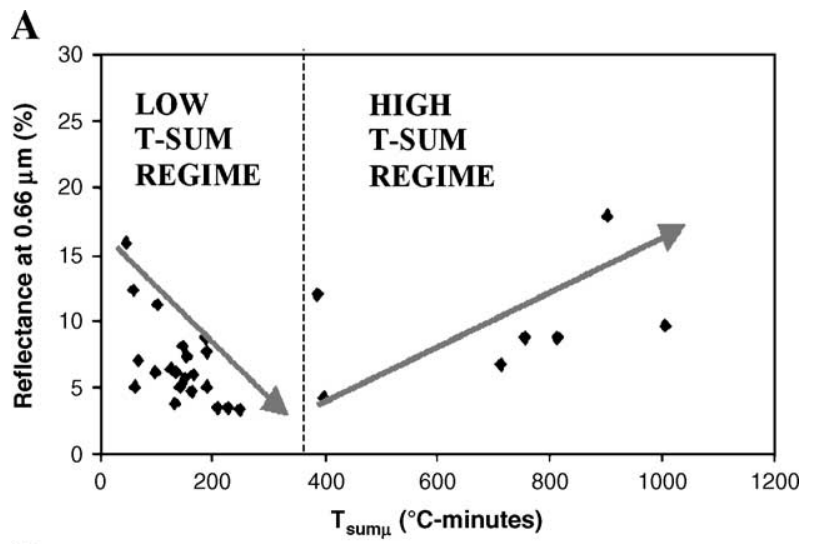

B

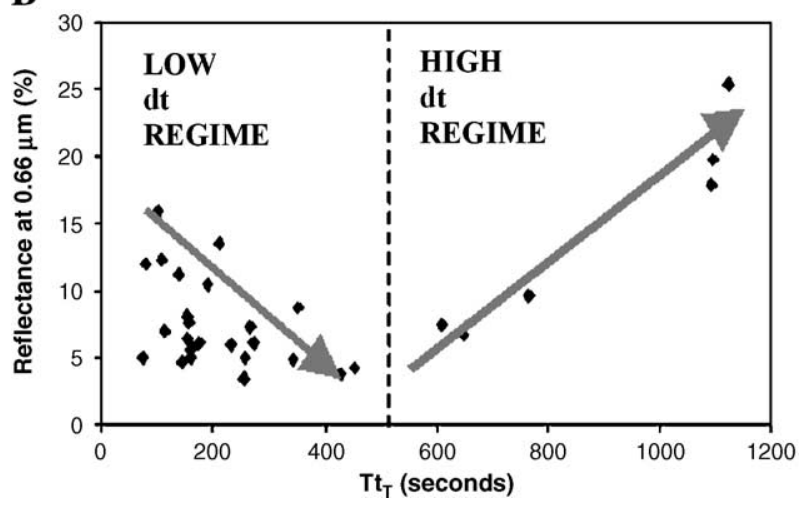

Fig. 7. Relationships between post-fire surface spectral reflectance and the integrated temperature with time and the fire duration. (A) Reflectance at $0.66 \mu \mathrm{m}$ with the mean measure of the integrated temperature with time. (B) Reflectance at $0.66 \mu \mathrm{m}$ with the top measure of the fire duration. $0.66 \mu \mathrm{m}$ was chosen for purely illustrative purposes.

in the large amount of scatter in reflectance seen in the low fire severity/duration regime (Fig. 7). However, as fire duration increases, there is a general reduction in the mean and variance of the surface spectral reflectance at all wavelengths. This is due to an increasing proportion of the surface being covered by black ash as fire duration (and thus the amount of fuel combusted) increases. This trend continues until the entire post-fire surface is covered with black ash. Given the scatter seen in the Figs. 7 and 8 relationships at low fire severity/duration, spectral reflectance observations cannot provide a diagnostic measure of fire severity/duration in this regime.

\subsubsection{Fire severity/duration regime threshold}

The threshold between the low and high fire severity/fire duration regimes represents the point at which black ash completely covers the post-fire surface due to sufficient fuel being combusted.

\subsubsection{High fire severity/duration regime:}

Within the high fire severity/duration regime, the main process affecting the post-fire surface spectral reflectance is believed to be the increased production of white mineral ash, which is the result of more complete combustion of the available fuel (Byram, 1959a; Schmidt et al., 2003). This results in the relatively high surface spectral reflectance of white ash at all wavelengths (Fig. 5B; Landmann, 2003). Observations during our experiment indicated that white ash is generally produced by the combustion of the existing coarse-grained black ash layer deposited on the surface during the earlier stages of the fire. We suggest that as fire duration increases, combustion completeness increases and more white mineral ash is produced, resulting in an increase in surface spectral reflectance. The quantity of white mineral ash produced per unit area can therefore be considered to relate to the fire severity, with more white ash produced, biomass combusted, and gases volatilised in higher severity fires than in lower severity fires (Landmann, 2003).

The quadratic relationships shown in Fig. 8 indicated that a particular post-fire surface spectral reflectance can result from two fires having essentially opposite fire durations. However, the use of band ratios utilising the visible (350$650 \mathrm{~nm})$ and shortwave-infrared $(1950-2250 \mathrm{~nm})$ observations yielded relationships that were linear with fire duration. The coefficient of determination $\left(r^{2}\right)$ for different wavelength combinations reveals statistically significant correlations $\left(r^{2}>0.75, n=34, p<0.001\right)$ between fire duration and reflectance ratios having numerator wavelengths between 350 and $550 \mathrm{~nm}$ and denominator wavelengths at 2034, 2158, or 2120-2140 nm (Fig. 9A). However, since atmospheric scattering increases markedly with decreasing wavelength, numerator wavelengths of 550 $\mathrm{nm}$ were preferred to those of shorter wavelengths, and the ratio of the spectral reflectance at $550 \mathrm{~nm}$ to that at $2140 \mathrm{~nm}$ is suggested as a potential burn severity index related to fire duration (Table 3).

The above analysis was repeated for the mean of the integrated temperature $\left(T_{\text {sum } \mu}\right)$, the fire intensity and the measures of $T_{\max }$. A comparison of Fig. $9 \mathrm{~A}$ and $\mathrm{B}$ demonstrate that $r^{2}$ values of the $T_{\mathrm{sum} \mu}$ ratios were higher, and maintained higher values over a wider range of wavelengths than the measure of fire duration at the top thermocouple $\left(\mathrm{dt}_{\mathrm{T}}\right)$. Table 3 illustrates that the use of the 550 to $2140 \mathrm{~nm}$ band ratio is potentially a versatile burn severity index since it exhibits a strong relationship to both the top thermocouple fire duration measure and the mean measure of integrated fire temperature with time. The assessment of similar relationships for fireline intensity produced a maximum $r^{2}$ of 0.43 for band ratios including $450 \mathrm{~nm}$ observations as the numerator (Fig. 9C), while the assessment of $T_{\max }$ at each thermocouple height produced no statistically significant relationships.

The bowl shaped nature of the relationship between surface spectral reflectance and fire severity has significant implications for burned area mapping algorithms, which generally assume a decrease in VIS-NIR spectral reflectance on burning (e.g. Eva \& Lambin, 1998; Trigg \& Flasse, 2000). In particular, the removal of senesced vegetation and the revealing of higher albedo soils, and in particular the additional laying down of a surface white 

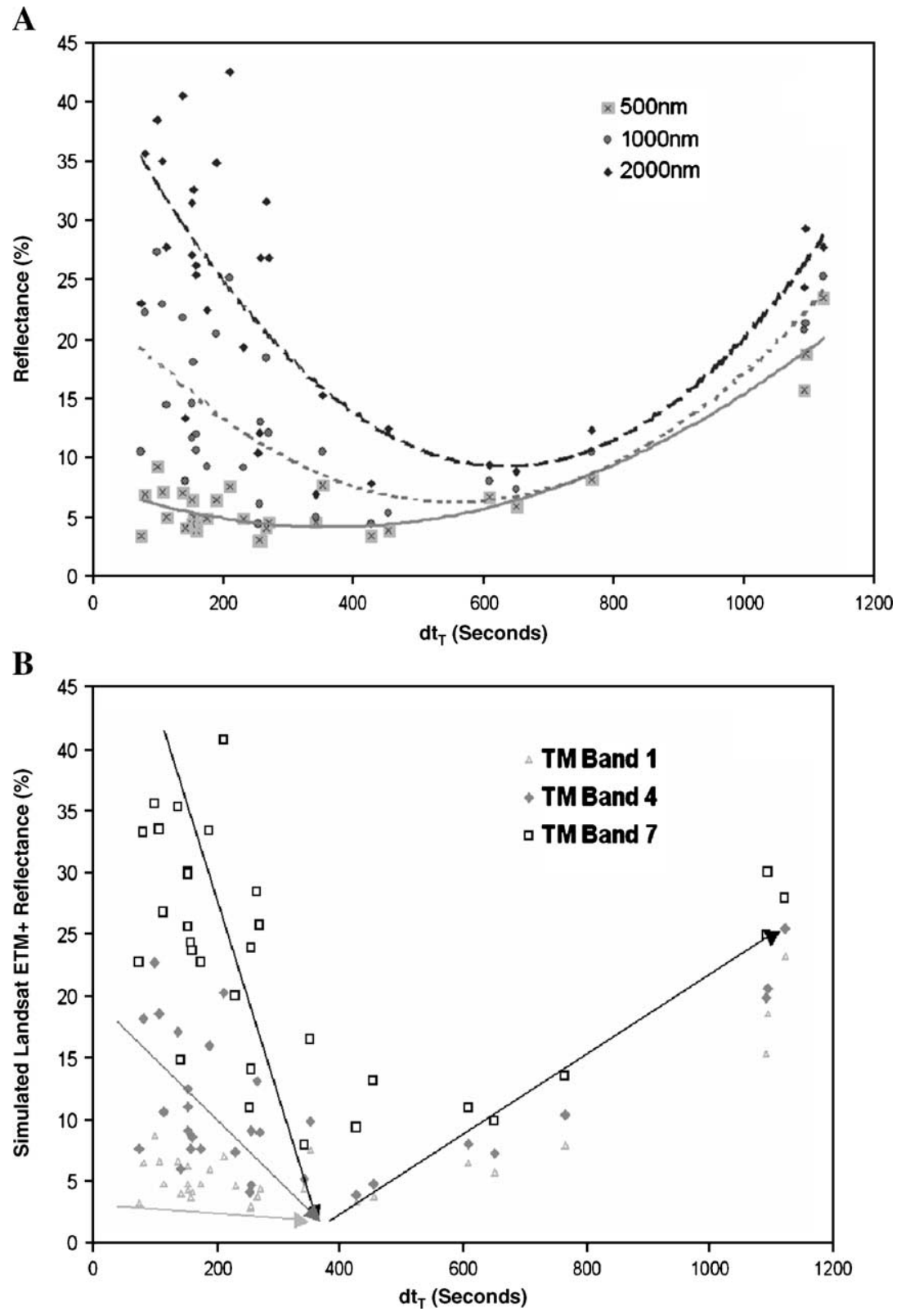

Fig. 8. Relationships between the fire duration, as measured by the top thermocouple, with (A) spectral reflectance at example wavelengths, and (B) the simulated $\mathrm{ETM}+$ spectral reflectance of the post-fire surface.

ash layer, can in some cases result in a surface spectral reflectance increase on burning (as opposed to the assumed reflectance decrease). As such, many current burned area mapping algorithms may fail to recognise such areas as burnt, yet our experiments show that it is in these very areas that most biomass is combusted since long fire durations and high biomass loads are required to form surface white ash layers. Of course, such white ash layers are generally confined to relatively small patches, and so the tendency of burned area mapping algorithms to misclassify such areas will be strongly influenced by the sensor spatial resolution.

Relationships linking fire severity to the simulated spectral reflectance measures made in the individual wavebands of the ETM+ sensor were also investigated. The effectiveness of the NBR (Eq. (4)) and ETM+ band ratios were also similarly investigated. No significant relationships was obtained between FLI or $T_{\max }$ and NBR. Statistically significant but relatively poor relationships were obtained between NBR and biomass combusted $\left(r^{2}=0.39, n=40, p<0.001\right)$ and nitrogen volatilised $\left(r^{2}=0.23, n=39, p<0.005\right)$, indicating that NBR is not an effective predictor of fuel or nitrogen loss in this environment. Comparison of NBR with each measure of $T_{\text {sum }}$ and dt produced statistically significant relationships at each thermocouple height, and the optimal relationship was obtained using $T_{\text {sum }}$ at the middle-of-sward height $\left(r^{2}=0.61, n=27, p<0.001\right)$ (Fig. 10A). However, this 

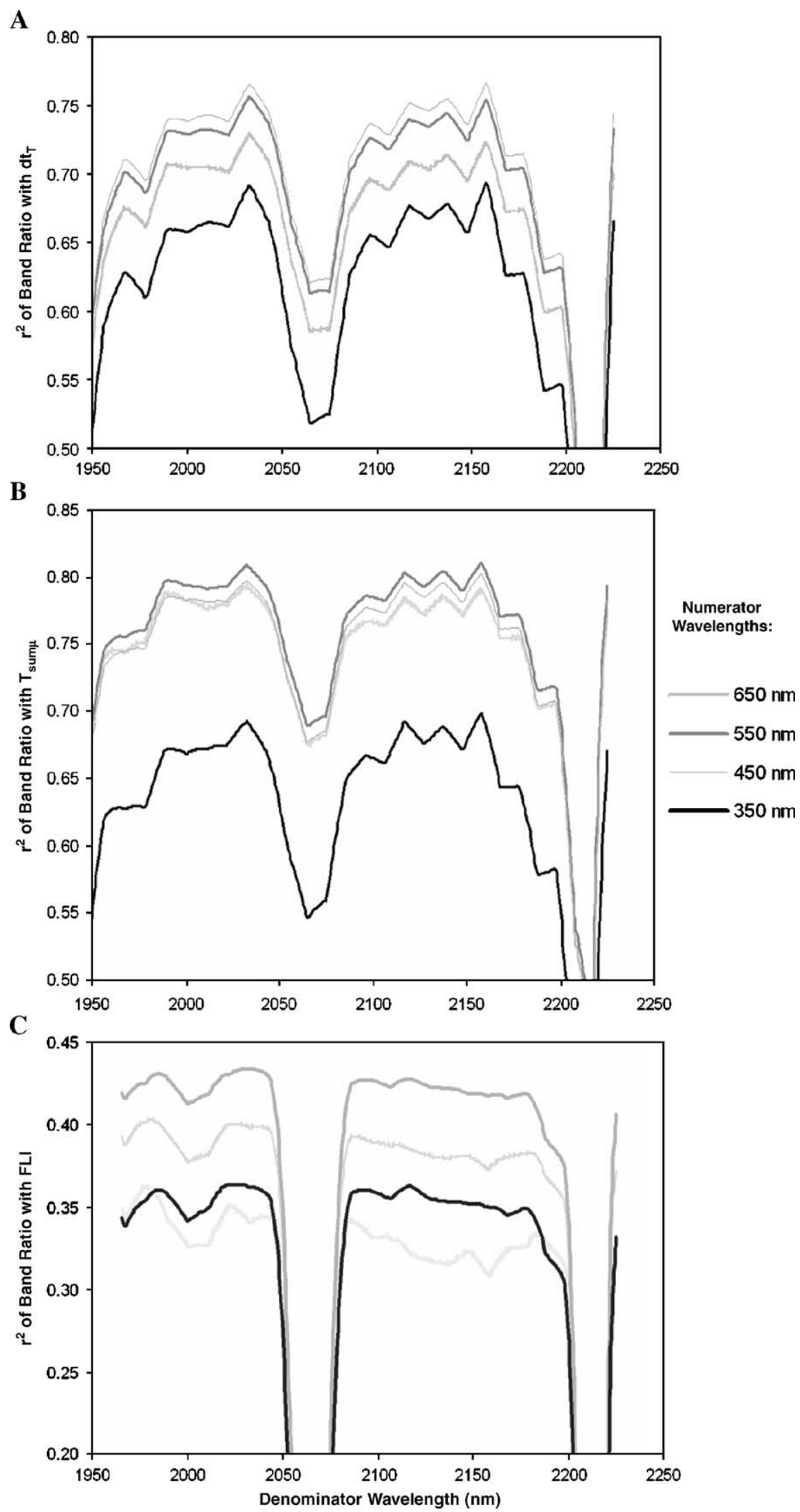

Fig. 9. Testing the ability of post-fire surface spectral reflectance ratios to produce linear relationships with (A) fire duration, (B) integrated temperature with time, and (C) fireline intensity. Correlations are between reflectance wavelength numerators between 350 and $650 \mathrm{~nm}$ (100 nm steps) and denominators between 1950 and $2250 \mathrm{~nm}(1 \mathrm{~nm}$ steps). 
Table 3

Statitsically significant relationships between spectrally-based fire characteristic measures $(y)$ and measures of fire severity $(x)$

\begin{tabular}{|c|c|c|c|c|c|c|}
\hline$y$ & $\mathrm{x}$ & Equation & $r^{2}$ & $n$ & Sig. ( $p$-value) & SE (model) \\
\hline NBR & $T_{\text {sumB }}$ & $y=0.0001 x-0.4402$ & 0.48 & 32 & $<0.001$ & 0.0989 \\
\hline NBR & $T_{\mathrm{sum} M}$ & $y=0.0004 x-0.4774$ & 0.61 & 27 & $<0.001$ & 0.0872 \\
\hline NBR & $T_{\text {sumT }}$ & $y=0.004 x-0.4473$ & 0.38 & 32 & $<0.005$ & 0.1098 \\
\hline NBR & $T_{\text {sum } \mu}$ & $y=0.0003 x-0.463$ & 0.55 & 34 & $<0.001$ & 0.0928 \\
\hline NBR & $\mathrm{dt}_{\mathrm{B}}$ & $y=0.0002 x-0.4512$ & 0.34 & 37 & $<0.001$ & 0.1083 \\
\hline NBR & $\mathrm{dt}_{M}$ & $y=0.0002 x-0.4651$ & 0.42 & 32 & $<0.005$ & 0.0994 \\
\hline NBR & $\mathrm{dt}_{\mathrm{T}}$ & $y=0.0004 x-0.4702$ & 0.53 & 32 & $<0.001$ & 0.0960 \\
\hline NBR & $\mathrm{dt}$ & $y=0.0002 x-0.4562$ & 0.39 & 34 & $<0.001$ & 0.1048 \\
\hline $550 / 2140$ & $\mathrm{dt}_{\mathrm{T}}$ & $y=0.0006 x+0.1478$ & 0.74 & 32 & $<0.001$ & 0.1076 \\
\hline $550 / 2140$ & $T_{\text {sum } \mu}$ & $y=0.005 x+0.1741$ & 0.81 & 34 & $<0.001$ & 0.0894 \\
\hline TM3/TM7 & $\mathrm{dt}_{\mathrm{T}}$ & $y=0.0005 x+0.212$ & 0.73 & 32 & $<0.001$ & 0.0976 \\
\hline TM3/TM7 & $T_{\text {sum } \mu}$ & $y=0.0005 x+0.224$ & 0.75 & 34 & $<0.001$ & 0.0880 \\
\hline TM2/TM7 & $\mathrm{dt}_{\mathrm{T}}$ & $y=0.0006 x+0.151$ & 0.75 & 32 & $<0.001$ & 0.0916 \\
\hline TM2/TM7 & $T_{\text {sum } \mu}$ & $y=0.0005 x+0.168$ & 0.77 & 34 & $<0.001$ & 0.0822 \\
\hline TM1/TM7 & $\mathrm{dt}_{\mathrm{T}}$ & $y=0.0006 x+0.113$ & 0.79 & 32 & $<0.001$ & 0.0880 \\
\hline TM1/TM7 & $T_{\text {sum } \mu}$ & $y=0.0005 x+0.134$ & 0.77 & 34 & $<0.001$ & 0.0803 \\
\hline
\end{tabular}

relationship is statistically weaker than that obtained through application of simple band ratios using the simulated ETM+ visible and shortwave infrared bands (Fig. 10B, Table 3). The considerable variation observed at the lower $T_{\text {sum } M}$ values is due to the multiple mixing effects previously identified within the low fire duration regime.

Consideration of the fire severity regimes identified in Section 4.3 identifies potential problems with the application of Landsat-type imagery to assess fire severity in this environment. The considerable heterogeneity of the surface component mixtures (i.e. unburned senesced vegetation, soils, and black ash) within the low severity regime, and the resulting scatter in Fig. $8 \mathrm{~A}$ and $\mathrm{B}$, suggests that $0 \mathrm{NBR}$ and other band ratio methods cannot be readily used as a diagnostic tool to quantify severity variations within this regime. However, the decrease in scatter at higher fire severities appears more promising. Although these results demonstrate that limitations exist in applying NBR and other ratio methods to infer severity within fires dominated by surface consumption (e.g. savannahs, rangelands, etc.), such relationships might be more significant in environments in which severity is defined through changes within multiple vegetation layers (i.e. surface and canopy effects within forests). A further problem arises with the small spatial scale of the white ash deposits noted in both our experimental fire plots and at the locations of surrounding natural fires. The largest patches of white ash, which were only present at low spatial densities (Fig. 11B), were associated with burnt fallen logs, and were around $\sim 4 \mathrm{~m}$ long by less than $1 \mathrm{~m}$ wide. This suggests that at the scale of Landsat ETM+, discrimination of spatial variations in fire severity will be problematic because the largest patches of white ash are very much smaller than the spatial resolution of the sensor. This issue is crucial to the practical implementation of a spectrally-based approach to mapping fire severity from satellite EO data and it is investigated further in the next section.

\subsection{The mixing properties of ash and the application of mixture models}

The effect of spatial resolution on a sensors ability to detect patches of white ash was investigated by assuming an optical mixture model for the individual surface components, and scaling up the results of the field experiment to that of the satellite imagery to be investigated. However, few if any research investigations exist that have evaluated which type of mixture model (linear or non-linear) is most applicable to the analysis of post-fire surfaces. It is known that the optical mixing of black and white particles of small diameter can be highly non-linear because of the tendency for photons scattered by the white material to be absorbed by the black material (thus failing to be detected by the sensor). This results in an over-representation of the signature of the black particles in the resultant reflectance spectrum, when compared to the actual physical proportion present (Clark \& Lucey, 1984).

Whether the optical mixing is linear or non-linear is largely controlled by the size of the particles present in the ash. If the particles are large (with respect to the wavelength of the electromagnetic radiation) the vast majority of photons will interact only with a single particle and there will be little or no multiple scattering, since this only occurs at the particle boundaries, and mixing will be linear. Patches of white and black ash composed of pure assemblages of these particle types were clearly evident in the field experiments and in the aerial photography (Fig. 11B) and can be expected to follow the assumptions of the linear mixture model. However, much smaller patches and particles were also noted in the field experiments, right down to scales only just resolvable by the human eye.

As particle size becomes smaller, the surface area to volume ratio decreases and the number of particle boundaries per unit volume increases. Therefore, there is more chance of multiple photon scattering between particles at 

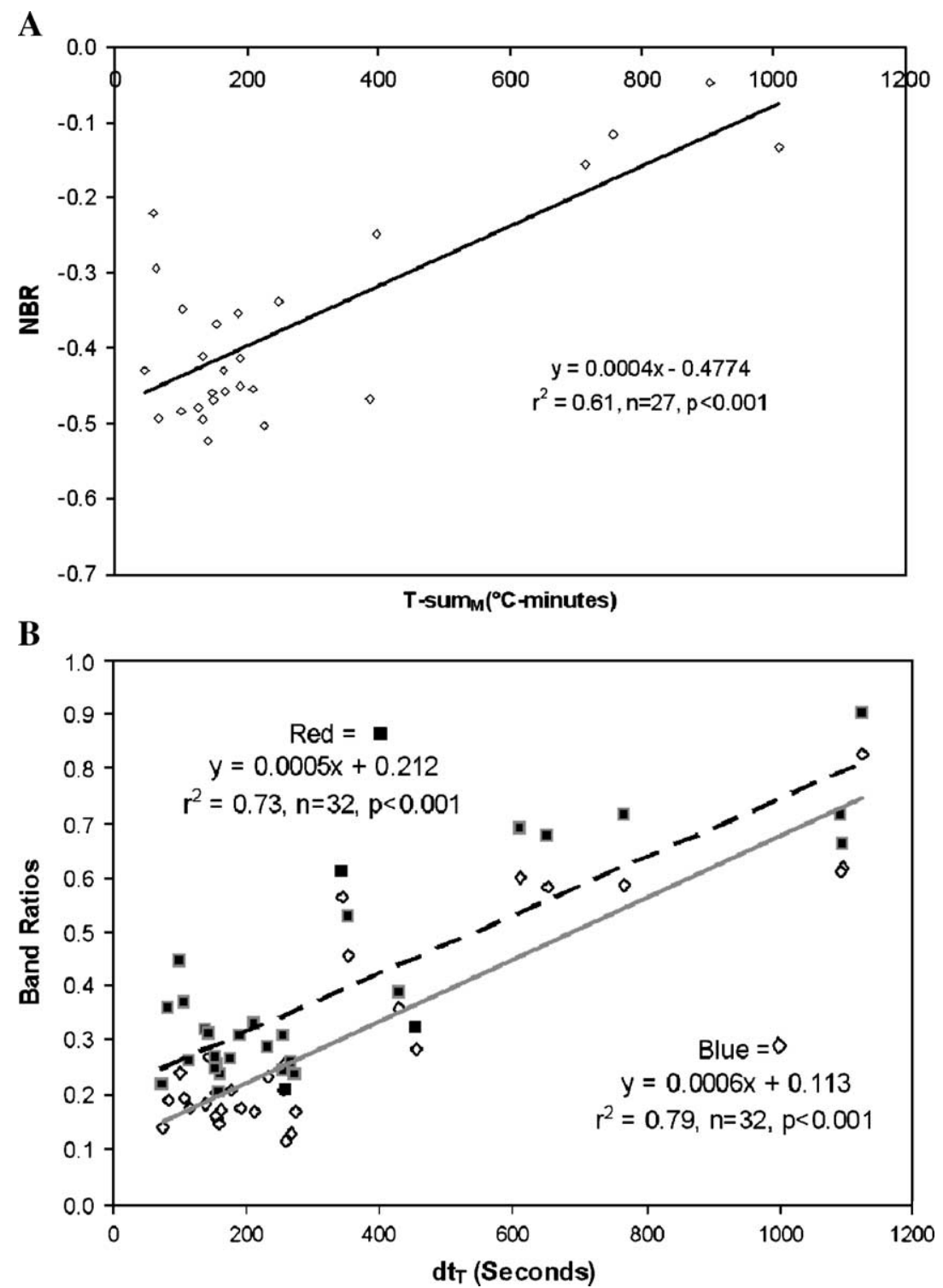

Fig. 10. Assessment of the surface spectral reflectance ratios within the simulated Landsat ETM+ bands. (A) Comparison between the normalised burn ratio (NBR) and the mean measure of $T_{\text {sum. }}$. B) The band ratios produced using the simulated ground-based reflectances within Landsat ETM+ Bands 1 and 7 , and Bands 3 and 7. The dashed and solid lines denote the best-fit linear relationships in each case.

boundaries, and so non-linearities can arise. A further nonlinear process manifests itself when the particle is so small that it approaches the materials optical path length. At this scale, photons can pass through a grain and interact with others. Such forms of non-linear mixing are modelled by the equations of Hapke $(1981,1993)$ and our field observations suggest that non-linear effects may play a role in ash reflectance at the small scale, whilst linear effects dominate at the larger scales. In order to determine the applicability of these models to areal and intimate mixtures of the different ash types, we examined the spectral properties of black and white ash, their linear and non-linear mixing properties, and included assessment of these in relation to ash particle size and the size of ash patches. The most appropriate optical mixing model was then used to evaluate the effect of spatial resolution on a sensor's ability to detect sub-pixel patches white ash.

\subsubsection{Particle grain size analysis}

White ash was dominated by particle sizes of 50 to 300 $\mu \mathrm{m}$, though larger particle sizes were present in the 300 to $1600 \mu \mathrm{m}$ size bracket. The spectral reflectance of white ash was found to be related to particle grain size. A particle class size increase from $50-75$ to $300-1600 \mu \mathrm{m}$ resulted in a spectral reflectance decrease of around $50 \%$ at all wavelengths (Fig. 12A). Therefore, white ash displays the same spectral reflectance variation with increasing grain size as has been observed in previous studies of minerals (e.g. Clark, 1983; Johnson et al., 1992). This might be expected as white ash (or mineral ash) is the incombustible 

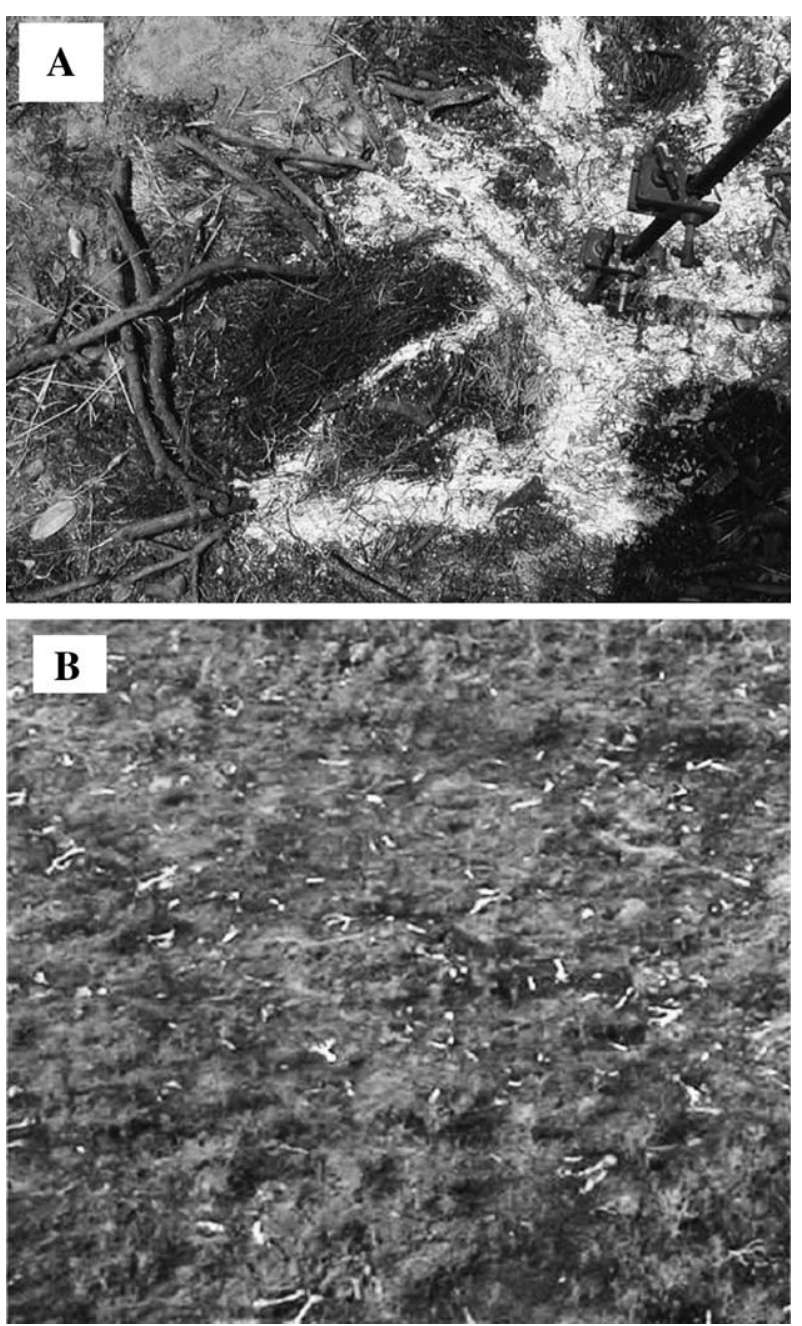

Fig. 11. Photographs of the spatial arrangement of white ash. (A) Photograph of one of the post-fire surfaces at the base of a thermocouple measurement stand. Areas of white and black ash can be clearly seen, and close examination indicates that where layers of both exist the smallergrained white ash always lays on top of the much coarser black ash. (B) Oblique aerial photograph showing patchwork of white and black ash deposits in northwestern Zimbabwe. In this case, the white ash primarily results from combustion of fallen trees, while the back ash results from combustion of the surrounding grass and litter. Photograph covers an area approximately 120 by $60 \mathrm{~m}$ in size, equating to $4 \times 2$ Landsat $\mathrm{ETM}+$ pixels.

mineral component of the vegetation that remains following a fire.

Black ash showed a directly opposite relation to that found with white ash, in that increasing black ash grain size resulted in increased spectral reflectance (Fig. 12B). In contrast to the white ash particles sizes being predominately within the 50 and $300 \mu \mathrm{m}$ size bracket, black ash was found to contain particles with size varying from 50 to greater than $1600 \mu \mathrm{m}$, some of which were clearly partially combusted fuel. The amount of uncombusted fuel particles present increased with the grain size class, and the increasing spectral reflectance with grain size appear to be directly related to this. This finding has important implications for the application of non-linear optical mixing models since such models require grain size estimates, whereas black ash is found not to exhibit a range of likely grain sizes (i.e. black ash cannot be said to have a 'characteristic grain size'). Within this study, this problem was overcome by applying the model to a single ash grain size class in order to determine the model's applicability at the fine scale. However, application of the model to remotely sensed imagery where a mixture of grain sizes is present is not possible with any accuracy because of these varying grain size effects.

\subsubsection{Mixture modelling}

The predicted spectral reflectance of the intimate mixture of black and white ash, modelled using the non-linear approach, produced values similar to the measured reflectance spectrum (Fig. 13). Model error remained at less than $10 \%$ at all wavelengths. The closest correspondence between modelled and measured reflectance occurred at wavelengths longer than $1.6 \mu \mathrm{m}$, and the maximum absolute percentage reflectance difference for these wavelengths is $5 \%$. These results are comparable to those of Johnson et al. $(1983,1992)$, who studied binary mixtures of rock powders having a particle size of $50 \mu \mathrm{m}$ and found mean percentage reflectance differences of less than 5\% over the $0.4-2.5 \mu \mathrm{m}$ range. These results, however, only report the potential of non-linear mixing within a single grain size bracket (i.e. $50-75 \mu \mathrm{m}$ ), which is unlikely to represent a real burned area as black ash has already been shown not to have a characteristic grain size.

Though very small-scale, fine-grained mixtures of black and white ash particles were evident in the field, larger patches of white ash dominated (with patch size of the order of many square centimetres to at most a few square metres). These larger patches of white ash are usually associated with completely combusted large woody debris (e.g. Fig. 11A) and this arrangement can be considered as somewhat akin to the checkerboard pattern used in the previously described laboratory study on optical mixing properties. Therefore, assuming the patches of white ash are sufficiently optically thick that the black ash or soil surface beneath does not influence the measured reflectance, then linear mixture modelling can be applied. During the laboratory mixing experiment, an areal combination of black and white ash spectra modelled as a linear combination slightly overestimated the spectral reflectance at all wavelengths when compared to the observations (Fig. 14). The percentage difference between the modelled and measured reflectances peaked at $8-12 \%$ at near-to-shortwave infrared wavelengths, but fell to $6 \%$ in the visible region (Fig. 14B). This difference is slightly higher than that found with the non-linear model but of the same order, and these results demonstrate that little difference exists between the ability of linear and non-linear optical mixing models to represent the reflectance of areal mixtures of black and white ash. However, since the linear mixture model does not require an 

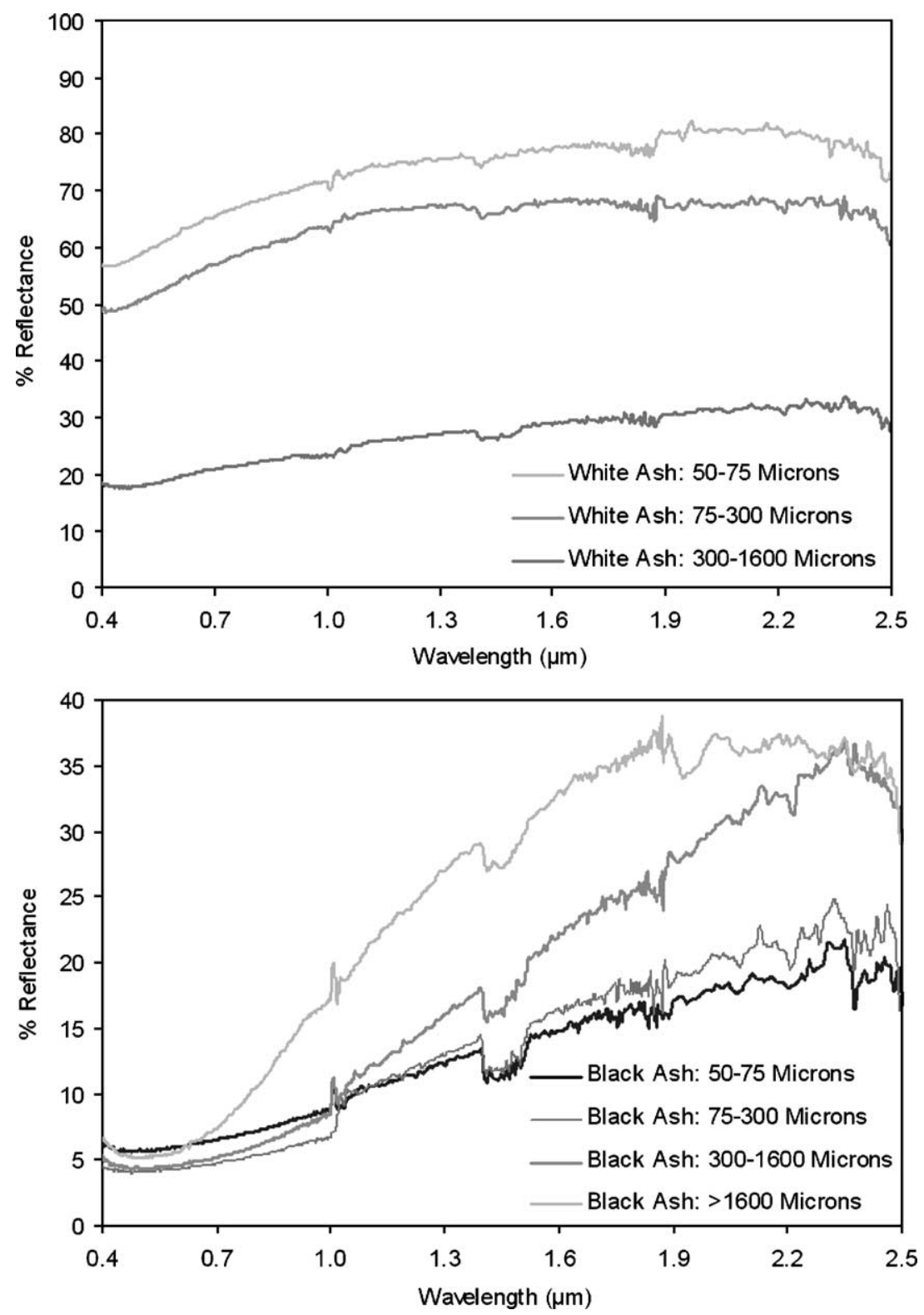

Fig. 12. The effect of grain size on the measured spectral reflectance of black and white ash. White ash reflectance decreases with increasing grain size (as per theory), whilst the opposite occurs for black ash. The particles sizes quoted are the minimum values within each size bracket.

estimate of the particle grain size, which is clearly problematic in the case of black ash, it is the most applicable to the natural situation where this is unknown and is a reasonable assumption at the spatial scales investigated in the laboratory study. Furthermore, in the natural environment white ash exists at a larger patch size than present in the laboratory setup, and at these larger scales the linear model is even more applicable.

\subsubsection{The potential of ETM+ and IKONOS for remote determination of fire severity}

The proven linear mixture model was used with the patch sizes derived from the digital air photo data (Fig. 11B) to estimate the relationship between image spatial resolution and a sensor's ability to detect white ash. At the scale of Landsat ETM+, the patches equate to a pixel proportion of $0.2 \pm 0.06 \%$, and though small this was the highest proportion of white ash seen in the many fireaffected areas examined. Using the linear mixing model, the maximum spectral reflectance $\left(R_{\text {PIXEL }}\right)$ of a pixel containing this mix of white and black ash patches was therefore estimated as:

$$
R_{\mathrm{PIXEL}}\left(8 * R_{\mathrm{B}} * 0.002\right)+\left(R_{\mathrm{B}} * 0.998\right) \cong 1.014 * R_{\mathrm{B}}
$$

where, based on our field spectra, we assume that the spectral reflectance of white ash is at most eight times that of black ash at any particular wavelength (Fig. 5B).

Therefore, at the scale of ETM+ even the largest patches of white ash noted in the field only increase the spectral 
A

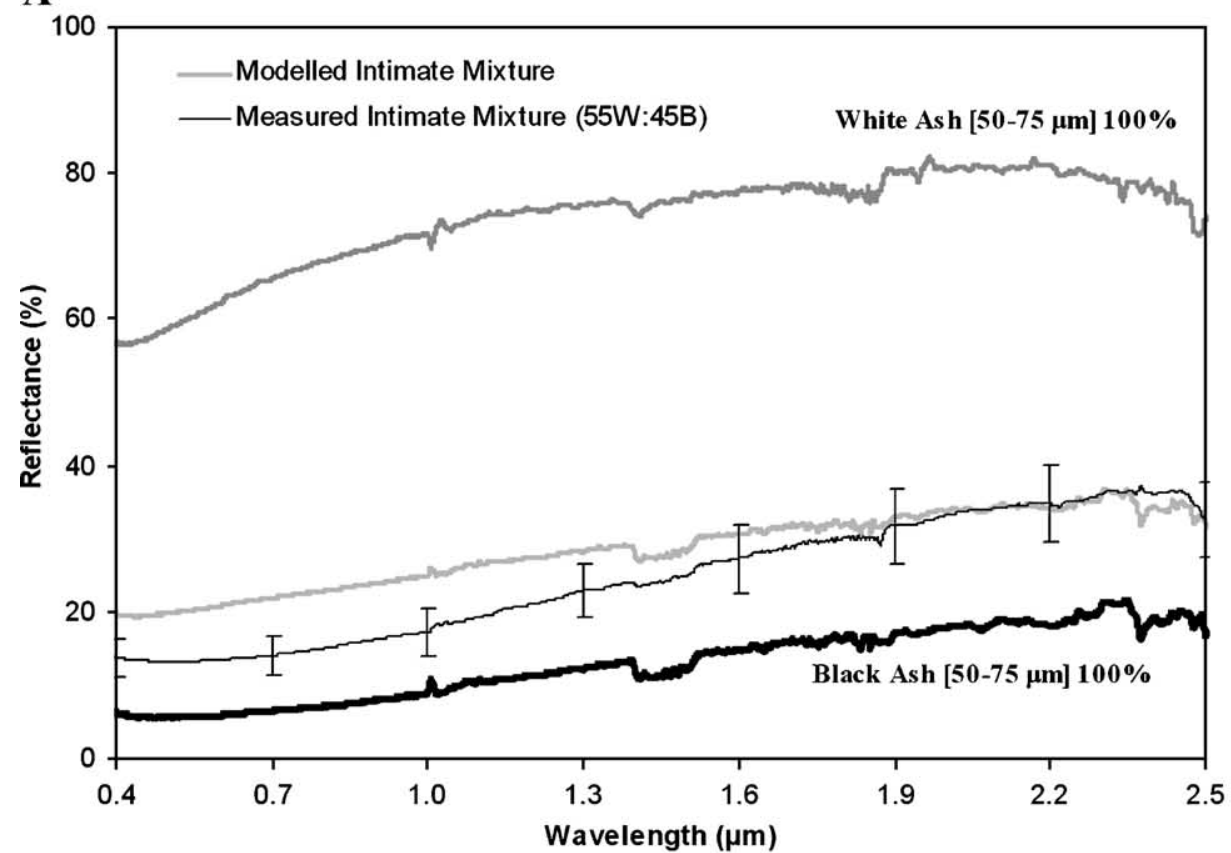

B

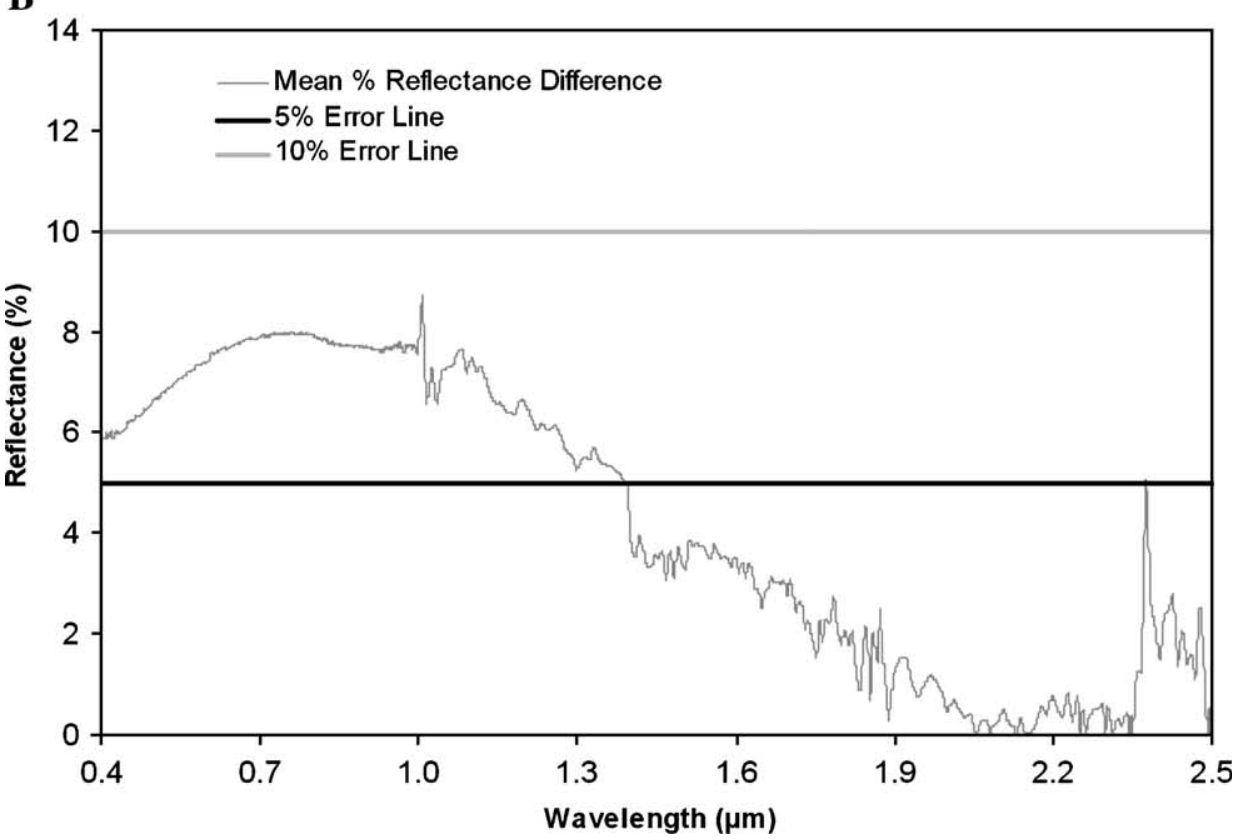

Fig. 13. Modelled and measured spectral reflectance of the intimate mixture of black and white ash. (A) Measured spectral reflectance of the white ash, black ash, and intimate mixture, along with the modelled spectral reflectance of the intimate mixture simulated using a non-linear mixing model. Error bars of 1 standard deviation $(n=40)$ spaced at $0.3 \mu \mathrm{m}$ intervals (to ease visualization) are displayed on the measured spectral reflectance. (B) Absolute reflectance difference between the measured and modeled spectral reflectance plots shown in (A).

reflectance of the fire-affected areas by $\sim 1.5 \%$ over that of the surrounding areas of solely black ash, and this difference is certainly too low to be accurately assessed using such data. Even with white ash patches an order of magnitude larger than those observed, the ETM+ pixel spectral reflectance would increased by only $15 \%$ above the black ash background, which when the low albedo of burned areas is considered (Fig. 5B) equates to a pixel integrated spectral reflectance increase from $\sim 5 \%$ to $6 \%$ at visible/NIR wavelengths and from $\sim 18 \%$ to $21 \%$ at shortwave infrared wavelengths. Again, it seems unlikely that such small differences could be meaningfully resolved, especially given the scatter noted in the relationships between spectral reflectance and measures of fire severity, for example, those shown in Fig. 8.

In summary, the results from the mixture modelling study suggest that sensors having spatial resolutions significantly higher than those of Landsat ETM+ will 

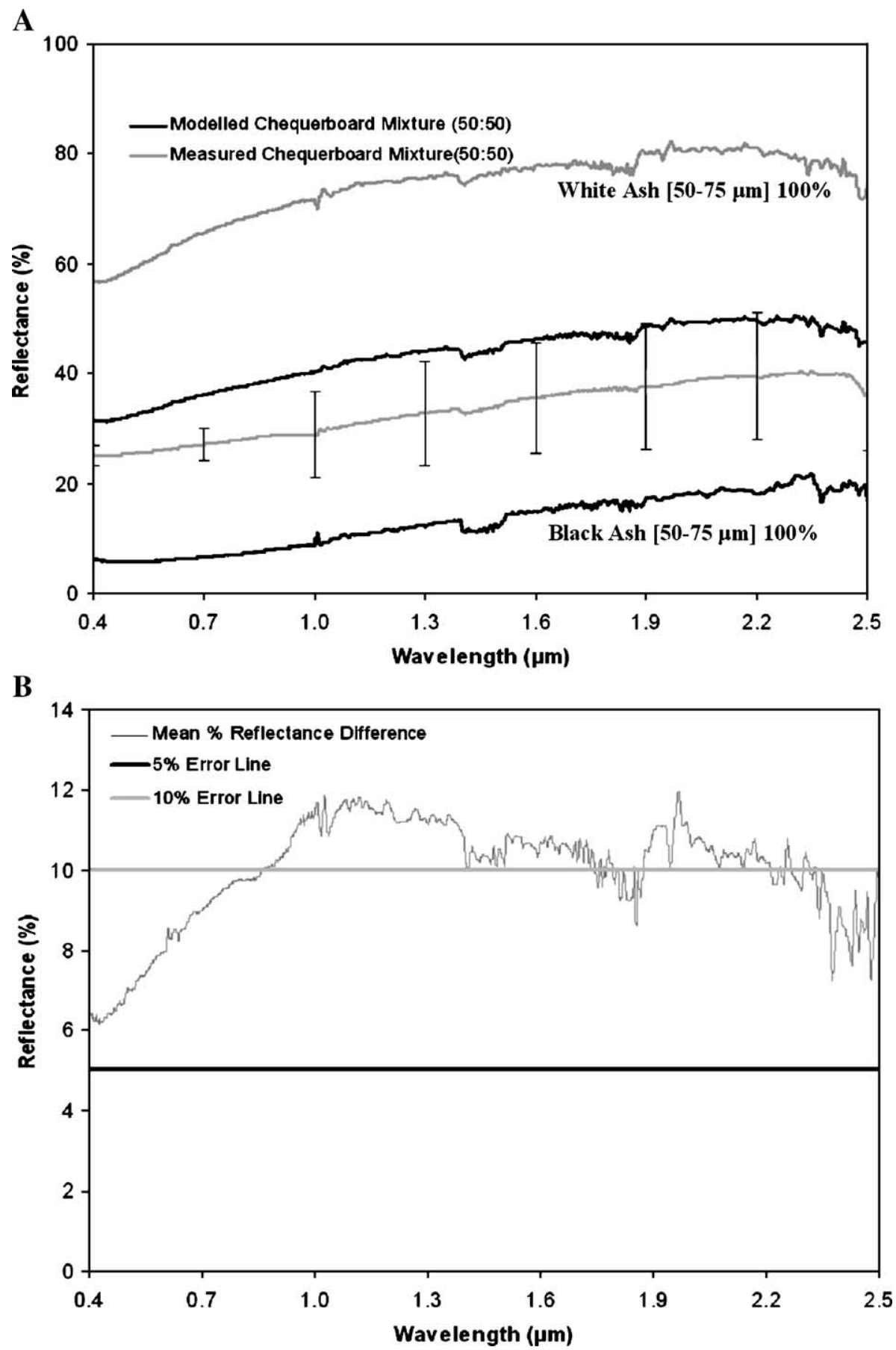

Fig. 14. Modelled and measured spectral reflectance of the checkerboard mixture of black and white ash. (A) Measured spectral reflectance of the white ash, black ash, and checkerboard mixture, along with the modeled spectral reflectance of the checkerboard mixture simulated using a linear mixing model. Error bars of 1 standard deviation $(n=40)$ spaced at $0.3 \mu \mathrm{m}$ intervals (to ease visualization) are displayed on the laboratory-measured spectral reflectance. (B) Absolute reflectance difference between the measured and modeled spectral reflectance plots shown in (A).

need to be used if post-fire patches of white ash are to be used as a remotely sensed surrogate to assess spatial variations in fire severity. However, higher spatial resolution systems offer a somewhat more realistic proposition. Using the $4 \mathrm{~m}$ spatial resolution, multi-spectral imagery available from IKONOS would increase the maximum pixel proportion of white ash to $10 \%$ (assuming the patch size noted in Fig. 11B), and this equates to a maximum spectral reflectance increase of $70 \%$ over that of the solely black as background. This spectral reflectance increase is certainly of a magnitude that could be useful in mapping spatial variations of fire severity, and this suggests that IKONOS-type imagery collected soon after a savannah fire would be suitable for this purpose. 


\section{Conclusions}

This work investigated the potential of fire characteristic measures (such as fire duration and integrated temperature with time) as indicators of fire severity, and specifically the relationship between such measures and the spectral reflectance of post-fire savannah surfaces. The research was based on analysis of instrumented, experimental fires carried out in Chobe National Park, Botswana. In these fires, surface spectral reflectance was found to be inversely related to fire severity, up to the point at which the burned surface becomes completely covered in black ash. Above this fire severity threshold, the combustion completeness of the ash becomes the dominant factor, and the surface spectral reflectance increases with increasing fire severity due to the formation of increasing quantities of white mineral ash. In the low fire severity regime there is much scatter in the relationships between the fire severity measures and the surface spectral reflectance, in part because it is dependent on the spectral reflectance of the soil background and the proportion of unburned fuel within the instrument field of view. However, in the high fire severity regime the scatter is markedly reduced since the soil and unburned fuel can be considered to be completely covered by ash, and the relationship is dominated by the areal proportion of white ash formed in the fire.

Fire duration and integrated temperature with time exhibit quadratic relationships with post-fire surface reflectance. Linear relationships were obtained between fire duration and wavelength varying ratios of post-fire surface spectral reflectance, with the optimal relationship being a ratio of the 450 and $2034 \mathrm{~nm}$ spectral reflectance observations. Atmospheric effects are more significant at shorter wavelengths, but a relationship of similar statistical significance was also found using 550 and 2140 $\mathrm{nm}$ wavelengths. Convolving the field-measured spectral reflectances with the bandwidths of the Landsat ETM+ sensor indicates that, within higher fire duration regimes, band ratios of ETM+ Bands 1, 2 and 3 with ETM+ Band 7 provide a burn severity index well related to both fire duration and integrated temperature with time. However, for the reasons cited previously, at lower fire durations significant scatter exists within this relationship.

The maximum instantaneous fire temperature was unrelated to the amount of biomass combusted, nitrogen volatilised, or to the spectral reflectance of the post-fire surface. This result indicates that methods that only acquire 'snap-shot' measurements of a fire are poor predictors of the overall fire effects. Although fireline intensity was found to somewhat related to nitrogen volatilised, particularly at higher FLI values, it was not well related to the spectral properties of the post-fire surface and thus has limited relevance to the retrospective remote sensing of fire severity.
In accordance with the suggestion of McNaughton et al. (1998), our results indicate that at the point-scale the surface spectral reflectance of burned savannah (predominately surface consumption) can be related to the severity of the causal fire at the same location. Where this technique can be extended over entire fire-affected areas, such spectral information should allow improved estimates of the amount of carbon and nitrogen volatilised in fires to be developed when compared to approaches relying simply on quantifying area burned. However, any attempt to use multi-spectral imagery to retrospectively estimate fire severity in larger, natural fires will be dependent upon the sensors spectral sensitivity to the presence of white ash, which is largely a function of the sensor spatial resolution. A linear mixture model, validated using ash samples collected in the field, was used to assess the ability of different satellite-based multispectral imagers to detect post-fire patches of white ash. Results indicate that in savannah environments IKONOStype very high spatial resolution sensors may be useful for this purpose, but that sensors with spatial resolutions comparable to those of Landsat ETM+ seem unlikely to be unable detect significant variations in white ash abundance.

It is possible that in higher-biomass, densely forested ecosystems the size and density of post-fire patches of white ash will be of such a size that detection from ETMlike sensors maybe possible, though in such environments the additional factors of significant topographic slopes, and variations in tree shadowing and tree mortality may pose new problems for the method. Furthermore, in forested environments where the evaluation of severity frequently involves the assessment of multiple vegetation layers, rather than just the surface layer, additional complications might arise through relating the surface spectral properties to EO-derived severity when the fires do not destroy the forest canopies.

\section{Acknowledgements}

Alistair Smith was supported by a NERC/GANE Thematic Program studentship (NER/S/R/2000/04057). Thanks are due to members of the Botswana Department of Agriculture and Department of Wildlife and National Parks for their assistance during the fieldwork. Thanks to Mark Van der Walle, Chief research biologist for Chobe National Park, for insights provided during fieldwork. Special thanks to Karen Anderson and staff of the NERC/ EPFS equipment pool located at the University of Southampton for training and loan of the GER 3700 spectroradiometer. Thanks to Bruce Hapke for his advice regarding the application of the non-linear Hapke equations. We are indebted to the editor and referees for their details and careful comments that greatly improved the content of this paper. 


\section{References}

Andreae, M. O. (1991). Biomass burning: Its history, use and distribution and its impact on environmental quality and global climate. Global biomass burning: Atmospheric, climatic and biospheric implications (pp. 3-21). Cambridge Mass: MIT Press.

Andreae, M. O. (1997). Emissions of trace gases and aerosols from southern African savannah fires. Fire in southern African savannahs: Ecological and atmospheric perspectives (pp. 161-183). Johannesburg: Witwatersrand University Press.

Andreae, M. O., \& Merlet, P. (2001). Emission of trace gases and aerosols from biomass burning. Global Biochemical Cycles, 15(4), 955-966.

Asner, G. P. (1998). Biophysical and biochemical sources of variability in canopy reflectance. Remote Sensing of Environment, 64, 234-253.

Borel, C. C., \& Gerstl, S. A. W. (1994). Nonlinear spectral mixing models for vegetative and soil surfaces. Remote Sensing of Environment, 47, $403-416$

Byram, G. M. (1959). Forest fire behaviour. Forest fire: Control and use (pp. 90-123). New York: McGraw-Hill.

Clark, R. N. (1983). Spectral properties of mixtures of montmorillonite and dark carbon grains: Implications for remote sensing minerals containing chemically and physically absorbed water. Journal of Geophysical Research, 88(B12), 10635-10644.

Clark, R. N., \& Lucey, P. G. (1984). Spectral properties of ice-particulate mixtures and implications for remote sensing 1 , intimate mixtures. Journal of Geophysical Research, 89(B7), 6341-6348.

Coffer III, W. R., Levine, J. S., Winstead, E. L., Cahoon, D. R., Sebacher, D. I., Pinto, J. P., et al. (1996). Source compositions of trace gases released during African savannah fires. Journal of Geophysical Research, 101, 23597-23602.

Crutzen, P. J., \& Andreae, M. O. (1990). Biomass burning in the tropics: Impact on atmospheric chemistry and biogeochemical cycles. Science, $250,1669$.

Debano, L. F., Rice, R. N., \& Conrad, C. E. (1979). Soil heating in chaparral fires: Effects on soil properties, plant nutrients, erosion and runoff. USDA Forest Service research paper, PSW-145. Pacific Northwest Forest and Range Experimental Station.

Díaz-Delgado, R., Lloret, F., \& Pons, X. (2003). Influence of fire severity on plant regeneration through remote sensing imagery. International Journal of Remote Sensing, 24(8), 1751-1763.

Elvidge, C. D. (1990). Visible and near infrared reflectance characteristics of dry plant materials. International Journal of Remote Sensing, 11(10), $1775-1795$.

Eva, H., \& Lambin, E. F. (1998). Burnt area mapping in Central Africa using ATSR data. International Journal of Remote Sensing, 19(18), $3473-3497$.

Foody, G. M., Lucas, R. M., Curran, P. J., \& Honzak, M. (1997). Non-linear mixture modelling without end-members using an artificial neural network. International Journal of Remote Sensing, 18(4), 937-953.

French, N., Goovaerts, P., \& Kasischke, E. S. (2004). Uncertainty in estimating carbon emissions from boreal forest fires. Journal of Geophysical Research, 109.

G.T.O.S. (2000). IGOS-P carbon cycle observation theme: Terrestrial and atmospheric components. GTOS-25.

Hao, W. M., \& Lui, M.-H. (1994). Spatial and temporal distribution of tropical biomass burning in 1980 with $5^{\circ} \times 5^{\circ}$ resolution. Global Biochemical Cycles, 8, 495-503.

Hao, W. M., Scharffe, D., Lobert, J. M., \& Crutzen, P. J. (1991). Emissions of $\mathrm{N}_{2} \mathrm{O}$ from the burning of biomass in an experimental system. Geophysical Research Letters, 18, 999-1002.

Hapke, B. (1981). Bidierctional reflectance spectroscopy. 1, Theory. Journal of Geophysical Research, 86, 3039-3054.

Hapke, B. (1993). Theory of Reflectance and Emittance Spectroscopy, Topics in Remote Sensing 3. Cambridge, UK: Cambridge University Press.
Hartford, R. A., \& Frandsen, W. H. (1992). When it's hot, it's hot...or maybe it's not! (Surface flaming may not portend soil heating). International Journal of Wildland Fire, 2(3), 139-144.

Hoffa, E. A., Ward, D. E., Hao, W. M., Susott, R. A., \& Wakimto, R. H. (1999). Seasonally of carbon emissions from biomass burning in a Zambian savannah. Journal of Geophysical Research, 104, 13841-13843.

Houghton, R. A. (1991). Biomass burning from the perspective of the global carbon cycle. Global biomass burning: Atmospheric, climatic and biospheric implications (pp. 326-339). Cambridge Mass: MIT Press.

Houghton, J. T., Meire Filho, L. G., Bruce, J., Lee, H., Callendar, B. A., Haites, E., et al. (1995). Climate change 1994: Radiative forcing of climate change. Cambridge: Cambridge University Press.

Hudak, A. T., \& Brockett, B. H. (2004). Mapping fire scars in a southern African savannah using Landsat imagery. International Journal of Remote Sensing, 25, 3231-3243.

Huete, A. R., \& Escadafal, R. (1991). Assessment of biophysical soil properties through spectral decomposition techniques. Remote Sensing of Environment, 35, 149-159.

Huntley, B. J., \& Walker, B. H. (1982). Ecology of tropical savannahs, Ecological studies 42. Berlin: Springer-Verlag.

Jacoby, P. W., Ansley, R. J., \& Trevion, B. A. (1992). Technical note: An improved method for measuring temperatures during range fires. Journal of Range Management, 45, 216-220.

Johnson, P. E., Smith, M. O., \& Adams, J. B. (1992). Simple algorithms for remote determination fro mineral abundances and particles sizes from reflectance spectra. Journal of Geophysical Research, 97(E2), $2649-2657$.

Johnson, P. E., Smith, M. O., Taylor-George, S., \& Adams, J. B. (1983). A semi empirical methods for analysis of the reflectance spectra of binary mineral mixtures. Journal of Geophysical Research, 88(B4), $3557-3561$.

Kamuhuza, A., Davis, G., Ringrose, S., Gambiza, J., \& Chileshe, E. (1997). The Kalahari transect: Research on global change and sustainable development in southern Africa. Stockholm: IGBP Report 42.

Kasischke, E. S., \& Bruhwiler, L. P. (2003). Emissions of carbon dioxide, carbon monoxide, and methane from boreal forest fires in 1998. Journal of Geophysical Research, 108, 8146.

Kaufman, Y. J., Kleidman, R. G., \& King, M. D. (1998). SCAR-B fires in the tropics: Properties and remote sensing from EOS-MODIS. Journal of Geophysical Research, 103(31), 955-968.

Keane, R. E., Burgan, R., \& van Wagtendok, J. (2001). Mapping wildland fuels for fire management across multiple scales: Integrating remote sensing, GIS, and biophysical modeling. International Journal of Wildland Fire, 10, 301-319.

Key, C. H., \& Benson, N. C. (2002). Measuring and remote sensing of burn severity. U.S. Geological Survey Wildland Fire Workshop, Los Alamos, NM October 31-November 3, 2000. USGS Open-File Report 02-11 (pp. 55).

Landmann, T. (2003). Characterizing sub-pixel Landsat ETM+ fire severity on experimental fires in the Kruger National Park, South Africa. South Africa Journal of Science, 99, 357-360.

Levine, J. S. (1990). Burning trees and bridges. Nature, 346, 511-512.

Levine, J. S. (1996). Introduction. Biomass burning and global change volume 1 remote sensing, modelling and inventory development, and biomass burning in Africa. Cambridge Mass: MIT Press.

McNaughton, S. J., Stronach, N. R. H., \& Georgiadis, N. J. (1998). Combustion in natural fires and global emissions budgets. Ecological Applications, 8(2), 464-468.

Miller, J. D., \& Yool, S. R. (2002). Mapping forest post-fire canopy consumption in several overstory types using multi-temporal Landsat TM and ETM data. Remote Sensing of Environment, 82, 481-496.

Molina, M. J., \& Llinares, J. V. (2001). Temperature-time curves at the soil surface in maquis summer fires. International Journal of Wildland Fire, $10,45-52$. 
Morgan, P., Hardy, C. C., Swetnam, T., Rollins, M. G., \& Long, L. G. (2001). Mapping fire regimes across time and space: Understanding coarse and fine-scale fire patterns. International Journal of Wildland Fire, 10, 329-342.

Nagler, P. L., Daughtry, C. S. T., \& Hgoward, S. N. (2000). Plant litter and soil reflectance. Remote Sensing of Environment, 71, 207-215.

Neary, D. G., Klopatek, C. C., Debano, L. F., \& Ffolliott, P. F. (1999). Fire effects on belowground sustainability: A review and synthesis. Forest Ecology and Management, 122, 51-71.

Pereira, J. M. C., Chuvieco, E., Beudoin, A., \& Desbois, N. (1997). Remote sensing of burned areas: A review. In E. Chuvieco (Ed.), A review of remote sensing methods for the study of large wildland fires (pp. 127184). Alcala de Henares: Departamento de Geografma, Universidad de Alcala.

Pereira, J. M. C., Sa, A. C. L., Sousa, A. M. O., Silva, J. M. N., Santos, T. N., \& Carreiras, J. M. B. (1999). Spectral characterisation and discrimination of burnt areas. In E. Chuvieco (Ed.), Remote sensing of large wildfires in the European Mediterranean Basin (pp. 123-138). Berlin: Springer-Verlag.

Perez, B., \& Moreno, J. M. (1998). Methods for quantifying fire severity in shrubland-fires. Plant Ecology, 139, 91-101.

Robinson, J. M. (1991). Fire from space: Global fire evaluation using infrared remote sensing. International Journal of Remote Sensing, 12(1), 3-24.

Roy, D. P., Giglio, L., Kendall, J. D., \& Justice, C. O. (1999). Multitemporal active-fire based burn scar detection algorithm. International Journal of Remote Sensing, 20(5), 1031-1038.

Schmidt, M. W. I., Masiello, C. A., \& Skjemstad, J. O. (2003). Final recommendations for reference materials in black carbon analysis. EOS, $84(52), 582-583$.

Scholes, M., \& Andreae, M. O. (2000). Biogenic and pyrogenic emissions from Africa and their impact on the global atmosphere. Ambio, 29, 23-29.

Scholes, R. J., Kendall, J., \& Justice, C. O. (1996). The quantity of biomass burned in southern Africa. Journal of Geophysical Research, 101, $23667-23676$.

Settle, J. J., \& Drake, N. A. (1993). Linear mixing and the estimation of ground cover proportions. International Journal of Remote Sensing, 14, $1159-1177$.

Shea, R. W., Shea, B. W., Kauffman, J. B., Ward, D. E., Haskins, C. I., \& Scholes, M. C. (1996). Fuel biomass and combustion factors associated with fires in savannah ecosystems of South Africa and Zambia. Journal of Geophysical Research, 101, 23551-23568.

Smith, A. M. S. \& Hudak, A. T. (in press). Estimating combustion of large downed woody debris from residual white ash. International Journal of Wildland Fire. doi:10.1071/WF05011.

Smith, A. M. S., Wooster, M. J., Drake, N. A., Perry, G. L. W., \& Dipotso, F. M. (2005). Fire in African savanna: Testing the impact of incomplete combustion on pyrogenic emissions estimates. Ecological Applications, $15,1074-1082$.

Smith, A. M. S., Wooster, M. J., Powell, A. K., \& Usher, D. (2002). Texture based feature extraction: Application to burn scar detection in earth observation satellite imagery. International Journal of Remote Sensing, 23(8), 1733-1739.

Stronach, N.R.H. (1989). Grass fires in the Serengeti National Park, Tanzania: Characteristics, behaviour and some effects on young trees, $\mathrm{PhD}$ Thesis, University of Cambridge, Unpublished.

Stronach, N. R. H., \& McNaughton, S. J. (1989). Grassland fire dynamics in the Serengeti ecosystem, and a potential method of retrospectively estimating fire energy. Journal of Applied Ecology, 26, 1025-1033.

Trigg, S., \& Flasse, S. (2000). Characterising the spectral-temporal response of burned savannah using in situ spectroradiometry and infrared thermometry. International Journal of Remote Sensing, 21, 3161-3168.

Trigg, S., \& Flasse, S. (2001). An evaluation of different bi-spectral spaces for discriminating burned shrub-savannah. International Journal of Remote Sensing, 22(13), 2641-2647.

Trollope, W. S. W. (1984). Fire behaviour, ecological effects of fire in South African ecosystems. Ecological studies, vol. 48. (pp. 149-179). New York: Springer-Verlag.

Trollope, W. S. W. (1996). Biomass burning in the savannahs of southern Africa with particular reference in the Kruger National Park in South Africa. Biomass burning and global change, Volume 1: Remote sensing, modelling and inventory development and biomass burning in Africa (pp. 260-269). Cambridge, Massachusetts: MIT Press.

Trollope, W. S. W., \& Potgieter, A. L. F. (1985). Fire behaviour in the Kruger National Park. Journal of the Grassland Society of South Africa, $2,17-22$

Trollope, W. S. W., Trollope, L. A., Potgieter, A. L. F., \& Zambatis, N. (1996). SAFARI-92 characterisation of biomass and fire behaviour in the small experimental burns in Kruger National Park. Journal of Geophysical Research, 101, 23531-23550.

van Wagtendonk, J. W., Root, R. R., \& Key, C. H. (2004). Comparison of AVIRIS and Landsat ETM+ detection capabilities for burn severity. Remote Sensing of Environment, 92, 397-408.

Ventura, J. M. P., Mendes-Lopes, J. M. C., \& Ripado, L. M. O. (1998). Temperature-time curves in fire propagating in beds of pine needles. Proceedings of the Conference on Fire and Forest Meteorology, 14, 699-711.

Waldrop, T. A., \& Brose, P. H. (1999). A comparison of fire intensity levels for stand replacement of table mountain pine (Pinus pungens Lamb.). Forest Ecology and Management, 113, 155-166.

West, O. (1971). Fire, man and wildlife as interacting factors limiting the development of vegetation in Rhodesia. Proceedings of the Tall Timbers Fire Ecology Conference, 11, 121-146.

Wooster, M. J. (2002). Small-scale experimental testing of fire radiative energy for quantifying mass combusted in natural vegetation fires. Geophysical Research Letters, 29(21), 2027.

Wooster, M. J., \& Zhang, M. J. (2004). Boreal forest fires burn less intensely in Russia than in North America. Geophysical Research Letters, 31, L20505.

Wooster, M. J., Shukiv, B., \& Oertel, D. (2003). Fire radiative energy for quantitative study of biomass burning: Derivation from the BIRD experimental satellite and comparison to MODIS fire products. Remote Sensing of Environment, 86(1), 83-107. 